HISTORICAL PERSPECTIVE

\title{
Out of Thin Air? Apport Studies Performed between 1928 and 1938 by Elemér Chengery Pap
}

\author{
Michael Nahm \\ Institute for Frontier Areas of Psychology and Mental Health (IGPP), Freiburg, Germany \\ nahm@igpp.de
}

Submitted June 3, 2019; Accepted July 19, 2019; Published December 30, 2019

DOI: https://doi.org/10.31275/2019/1575

Copyright: Creative Commons CC-BY-NC

\begin{abstract}
Physical mediumship is characterized by the occurrence of phenomena that seem to defy currently prevailing standard theories of physics, such as inexplicable movements of objects (macro-psychokinesis) and the seemingly unexplained materialization of objects, sometimes in closed spaces (apports). Nevertheless, systematic investigations into apport phenomena have barely been performed. The present article introduces one of the few exceptions. The studies were conducted by Elemér Chengery Pap from 1928 to 1938 in Budapest. He summarized his research in a voluminous but little-known Hungarian treatise that ranks among the largest monographs of experimental parapsychology written by a single investigator. His book contains descriptions of some the most spectacular occurrences recorded in physical mediumship. One medium in particular, Lajos Pap, allegedly produced apports that ranged from solid objects, various liquids, snow, plants, ensembles of living insects, crawfish, to living vertebrates up to the size of a sparrow hawk. After presenting an overview on the book's contents and some of the most remarkable phenomena described therein, I summarize the results of an experimental series performed with Lajos Pap by another Hungarian-born researcher, Nandor Fodor. Drawing from Fodor's and also others' observations, I demonstrate that Chengery Pap's research approach contained remarkable loopholes that devalue his effort to leave a supposedly objective report to posterity. The authenticity of Lajos Pap's phenomena thus remains questionable. Nevertheless, Chengery Pap's extensive treatise remains of historical significance in parapsychology and provides an instructive example highlighting difficulties in studying physical mediums.
\end{abstract}

Keywords: Physical mediumship_apports—Elemér Chengery Pap—Lajos Pap-Tibor Molnar — Nandor Fodor-Maria Silbert 


\section{Introduction}

Just as in other research disciplines, parapsychological treatises published in languages other than English are often little-known among the main community of experts. Additionally, the more specific the field of research, and the more unfamiliar the language, the more likely the work stays little-known or becomes practically forgotten. Still, such publications can represent important research contributions that deserve wider attention. In the context of physical mediumship, this is exemplified by translations of Icelandic sources on the medium Indridi Indridasson (Gissurarson \& Haraldsson, 1989; Haraldsson 2011, 2012; Haraldsson \& Gissurarson, 2015), by Polish sources on Franek Kluski (Weaver, 2015) and Eusapia Palladino (Ochorowicz, 2018a, 2018b), by Portuguese, Italian, and German sources on Carlos Mirabelli (Nahm, 2017), by Italian sources on Palladino (Bottazzi, 2011); or, regarding macro-physical phenomena in the context of a mystic, by the translations of old Italian sources on Joseph of Copertino (Grosso, 2016, 2017). In the present article, I present an overview of one of the most voluminous monographs on physical mediumship published, the Hungarian treatise Új Látóhatárok Felé [Toward New Horizons] authored by Elemér Chengery Pap (1938). This amply illustrated book contains a summary of the author's investigations performed between 1928 and 1938 on phenomena of physical mediumship that focused on psychokinetic phenomena (inexplicable movements of objects) and apport phenomena (physical objects and even living organisms that appear in an inexplicable manner, often inside a room or a locked location).

\section{Elemér Chengery Pap (1869-?)}

Chengery Pap was born on July 29, 1869. He held the office of the chief chemist of the Hungarian Civil Service in Budapest before retiring. Among other duties, he was responsible for the quality control of wine. However, he had been born into a family with a religious and spiritualistic attitude, and he came to know many of the leading personalities of the spiritualistic scene in Hungary, including one of the founding fathers of Hungarian spiritualism, Adolf Grünhut, with whom he became acquainted in 1898 (Gyimesi, 2016). Owing to his scientific background, Chengery Pap intended to study mediumistic phenomena by applying scientific methods, and from 1928 onward the opportunity arose due to his personal contact with two Hungarian physical mediums, Tibor Molnar (presumably 1900-?) and Lajos Pap (1883-1938), to whom he was not related. In 1932, he even established a "metapsychical laboratory" that was specifically designed to ensure optimal control conditions for his investigations. It also contained 
a museum in which all apported objects were exhibited in show cases. In addition to his magnum opus (Chengery Pap 1938), numerous articles in Hungarian newspapers and a few other Hungarian articles, Chengery Pap also published several reports about his work especially with Lajos Pap in German (Chengery Pap, 1930-1931, 1933a, 1934, 1935, 1935-1936; Chengery Pap \& Blacher, 1936) and one in English (Chengery Pap, 1933b). Unfortunately, I was unable to find out much about Chengery Pap's activities after 1938, or about how and when he died. Nevertheless, he published a small Hungarian booklet on mediumistic matters in 1941 (Chengery Pap, 1941), and according to Cornelius Tabori he was "still going strong" in 1942, "editing the monthly of the Hungarian Metapsychical Society though for a while it had to be suspended" (Tabori, 1951:242). The apport museum, in any case, was destroyed during the communist regime after the Second World War (Kürthy, 1999).

In the following sections of this article, I will first present an outline of the contents of Chengery Pap's book. Then, I will summarize noteworthy passages, beginning with reports of two sittings with Austrian medium Maria Silbert (1866-1936) that Chengery Pap attended, and continue with general overviews on the life and the phenomena reported from Molnar and Lajos Pap, drawing also from the German literature and other authors who wrote about their mediumship. Thereafter, I will describe the experimental laboratory that Chengery Pap established to study physical mediumship, and some of the most remarkable phenomena Chengery Pap reported from Lajos Pap, particularly apports. Finally, as is recommended in writings on the fraud-loaded field of physical mediumship, I will discuss the limitations of Chengery Pap's experimental approach, and comment especially on an unfavorable appraisal of Lajos Pap's mediumship advanced by another Hungarian-born psychical researcher, Nandor Fodor (1895-1964). ${ }^{1}$ A comparison of their investigative approaches and their reports on obtained results demonstrates that Chengery Pap's proceedings contained considerable loopholes that ultimately devalue his attempt to compile a supposedly objective research document. Nevertheless, his voluminous treatise remains of historical significance in parapsychology and offers methodological lessons highlighting difficulties in studying physical mediums.

\section{Új Látóhatárok Felé [Toward New Horizons] - An Outline of the Book}

In total, Chengery Pap's book encompasses 573 pages of small print and 86 images and photographs. In addition, it includes 32 plates with even more photographs. The book's first parts comprise several introductory sections 
on mediumship that end on page 129. They include a translated chapter written by Sir Oliver Lodge (1851-1940) on the "spirit hypothesis," and a preface written by Latvian/German Carl Blacher (1867-1939), a professor of chemistry in Riga (Latvia) with whom Chengery Pap corresponded because of the latter's own studies into apport phenomena (e.g., Blacher, 1926, 1931-1932, 1933, 1937). Other sections provide general introductions into different forms of trance and mediumship, such as talking, writing, painting, and especially physical mediumship. Regarding the latter, Chengery Pap described typical developments of physical mediums, their phenomena, how séances are held, and possible ways to produce fraudulent phenomena. He introduced other ostensible apport mediums, including the ones Blacher worked with, and Mr. Wolf (a pseudonym for Prokop Vlček), a young man with whom physician Dr. Jan Šimsa experimented in Prague (e.g., Šimsa, 1931, 1934). Moreover, Chengery Pap reported on the sittings with Maria Silbert that he attended in 1928 and 1932 in Graz, Austria.

From pages 130 to 160, Chengery Pap provided an outline of the development of Lajos Pap's mediumship, the control measures performed before and during sittings, the séance rules, and the "laboratory" in which the sittings were held starting in 1932. On pages 160 to 350, Chengery Pap described in detail 35 sittings in which remarkable phenomena occurred. They are based on notes that were taken down immediately after or during the séances. Starting in September 1936, the events during the séances were dictated to a shorthand writer who sat outside of the experimental room. Pages 351 to 372 contain considerations about apports of previously destroyed objects that seemed to reappear intact at sittings. In the section from page 373 to 540, short descriptions of all sittings and of all spontaneous phenomena Chengery Pap observed with mediums Molnar and Lajos Pap are given in chronological sequence; some of the more interesting occurrences are presented more extensively (in addition to the sittings that were already described in the preceding sections). In total, this section contains 266 reports. Of these, 57 relate to spontaneous apport phenomena that were attributed to Molnar in 43 cases, to Lajos Pap in 7 cases, and in 7 other cases both mediums were present but it remained unclear who had been responsible for producing the apports. Regarding the 209 séances held between 1928 and 1938, both mediums were present at 70, Lajos Pap as the sole medium at 124, and Molnar as the sole medium on 15 occasions. From page 541 onward, the book contains several overview sections. For example, the names of all (guest-) visitors at each séance are given, and a list of articles about Chengery Pap's research that were published in Hungary and elsewhere is provided. The book concludes with a detailed table of contents and the errata. 


\section{Elemér Chengery Pap's Sittings with Maria Silbert}

Maria Silbert (1866-1936) was a widely known Austrian physical medium. On the one hand, she was known for eliciting large-scale physical anomalies in full light. On the other hand, she and her sittings were hardly controlled in terms of scientific standards. ${ }^{2}$ Typical phenomena reported from Silbert's sittings include raps, powerful psychokinetic movements of tables and other objects, the latter's dematerialization and rematerialization (allegedly, even from within a locked safe) (Evian, 1937?), and their being inexplicably engraved with signs and letters, especially with the name "Nell," as her control personality called herself. When the lights were dimmed and it was relatively dark, bright flashes and other mysterious lights were regularly observed. The summaries of the two sittings with Silbert provided below illustrate typical séances of hers.

Chengery Pap's first sitting with Silbert took place on May 4, 1928. He arrived at Mrs. Silbert's home at 5:30 in the afternoon together with Tibor Molnar and two other women from Graz, Mrs. Felix and Mrs. Dettelbach. They sat around a table of about $1 \times 1.3 \mathrm{~m}$ size in the bright light of late afternoon; Chengery Pap sat opposite Mrs. Silbert. While the sitters conversed about psychical matters, faint raps on the table and a cupboard behind Silbert were heard, and first touches of their legs were reported. Then, Chengery Pap placed his watch on the wooden boards that connected the table legs at about $15 \mathrm{~cm}$ height above the floor, hoping it would be engraved by "Nell" in the characteristic manner. For the same purpose, Molnar placed his silver cigarette etui (a small case) on these boards, and Mrs. Dettelbach her golden wristwatch. The touches became stronger, and they felt like their legs beneath the table were being squeezed by a strong hand. Likewise, the raps became louder. At 6:15, Mrs. Felix, who sat at the long end of the table between Chengery Pap and Mrs. Silbert, shouted out in surprise that her chair was being pulled from behind, and she was afraid that she would fall down. Chengery Pap reported that he saw the chair moving about 20-25 cm toward the back. Molnar claimed that his neck was squeezed from behind by something that felt like a hand, although he sat in front of a closed window. Thereafter, the objects from the wooden boards repeatedly fell down from it, seemingly without being touched, and the sitters placed them onto the board again. At one point, the sitters found that the inside of Molnar's cigarette etui was engraved with the word "Nel" and two triangles (Figure 1A). Furthermore, when Mrs. Silbert conversed, gesticulating with both hands with her elbows resting on the table, Mrs. Dettelbach's wristwatch suddenly dangled from Mrs. Silbert's forefinger. Even though Chengery Pap was looking directly at Mrs. Silbert at that moment, he didn't see how the watch appeared on her hand. It just seemed 


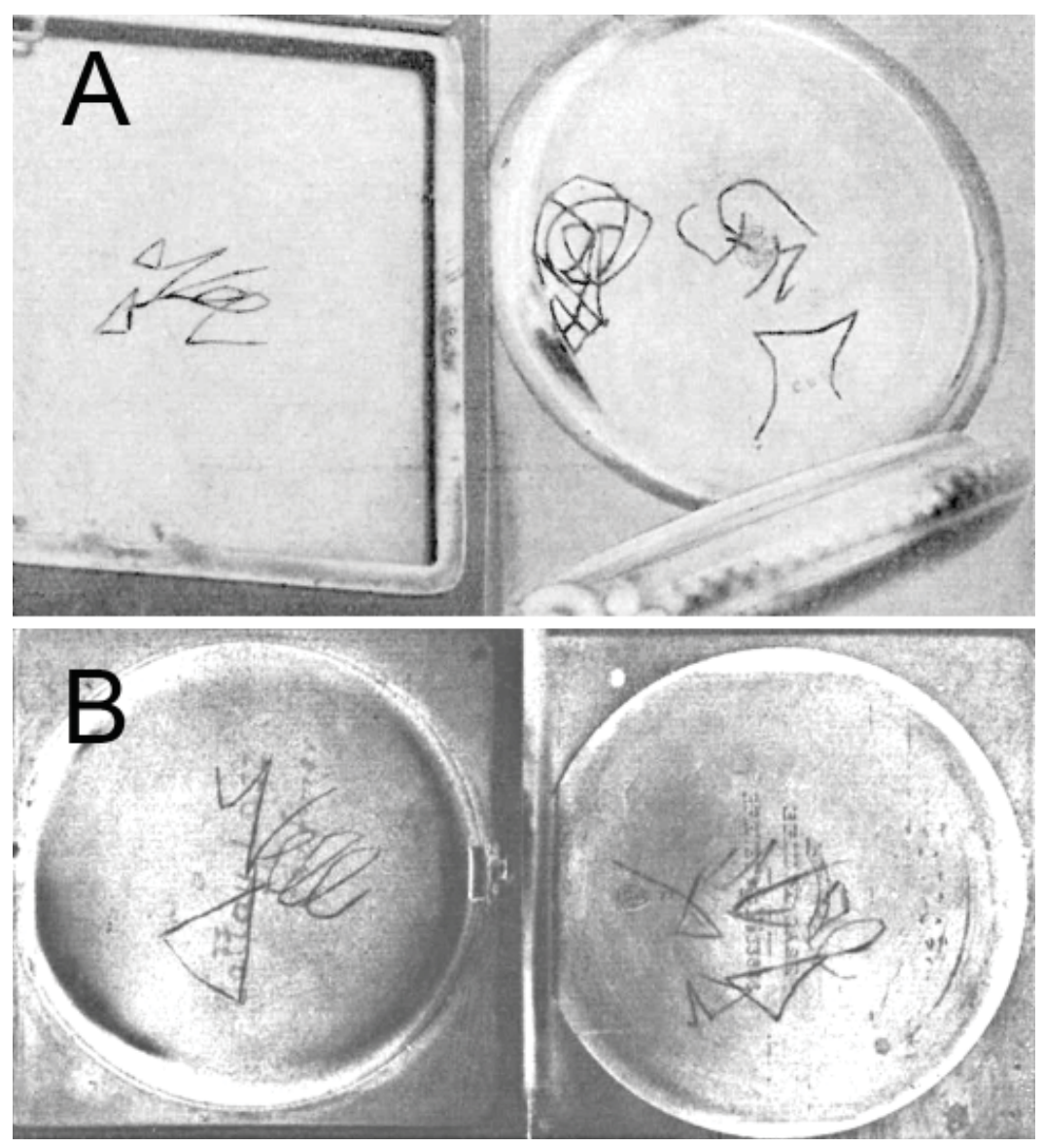

Figure 1. (A) Engravings obtained during a sitting with Maria Silbert on May 4, 1928, on Tibor Molnar's cigarette etui (left) and Elemér Chengery Pap's watch (right) (Chengery Pap, 1938:119).

(B) Engravings obtained during a sitting with Maria Silbert on May 18, 1932, on Laszlo Vattay's watch (Chengery Pap, 1938:123).

to be there from one moment to the next, although immediately before it had still lain on the wooden board below the tabletop and above the floor. The word "Nel" was engraved on the outside of the wristwatch. The distinct touches on the legs continued, and when Chengery Pap held his hand beneath the table, it felt as if it was pressed by several fingers. Meanwhile, dusk had set in, but it was still light enough to observe everything in the room well. 
During their ongoing conversation, Mrs. Silbert suddenly closed her right hand into a fist, and when she opened her fingers again Chengery Pap's watch lay on her palm. He stressed that Mrs. Silbert's hands had always remained on or above the table. The inside of the watch's lid was engraved with the letters "F. N." (for "Fredericus Nell") with two other scribblings (Figure 1A). Thereafter, Chengery Pap reported hammer-like strokes on the table surface, and he mentioned table levitations, but he didn't describe them further.

Chengery Pap visited Mrs. Silbert a second time on May 18, 1932. This time he was accompanied by both mediums Tibor Molnar and Lajos Pap, and by a friend of his, Laszlo Vattay. In addition, an acquaintance of Mrs. Silbert, Mr. Reich, participated in the sitting. Again, they sat around the wooden table in the dining room at 5:30 in the afternoon. However, Chengery Pap did not report his experiences of the sitting in person, but he reprinted the report by Vattay who had already published his own account in the Hungarian journal Metapsychikai Folyóirat [Metapsychical Journal] in 1933. Vattay stressed that he moved back from the table with his chair after he felt the first touches on his legs to have a better view of what was happening under the table. When his left knee was touched twice, he didn't see anything that might have caused these touches. As in the séance described before, many raps and touches were reported by the sitters, and they placed various objects on to the wooden boards under the table above the floor in order to receive engravings or writings on them. Vattay observed these objects closely. On one occasion, he saw a postcard fall down from the boards seemingly by itself, and at 7:15 he even saw his watch, which had already fallen to the floor from the board, suddenly vanish in an inexplicable manner. Three-quarters of an hour later, this watch fell unexpectedly down on his left knee and onto the floor. It contained several scribblings, including two engravings of the name "Nell" (Figure 1B). At about 8 o'clock, Mrs. Silbert stood up from her chair, and held her hands open toward the ceiling. Lajos Pap's watch suddenly fell into her hands from above, and then farther to the floor. Shortly thereafter, she turned in another direction, and Molnar's cigarette etui fell into her hands, seemingly out of the air. Loud raps continued to be heard, at times from two different locations in perfect unison. This was supposed to show that these raps were caused by one and the same agency. Vattay concluded his report with theoretical considerations about the observed phenomena, which he considered genuine. In contrast to Chengery Pap, however, he didn't believe that they were caused by a spirit of a deceased person.

In the following section, I'll provide some background information on the physical mediums Tibor Molnar and Lajos Pap, beginning with Molnar. 


\section{Tibor Molnar (Presumably 1900-?)}

Chengery Pap began to experiment with Tibor Molnar systematically in July 1928 (Chengery Pap, 1930-1931). However, readers of his book don't learn much about him, and, without explaining why, Chengery Pap stopped working with him in 1932. In a conversation with Fodor, he stated that he broke relations with Molnar because the latter had an undesirable effect on Lajos Pap (Fodor, 1936?). Somehow, it seems that Molnar must have fallen from grace with Chengery Pap. In former publications, Chengery Pap typically used Molnar's full name and described his character in positive terms (Chengery Pap, 1930-1931, 1932a), but he only referred to him as "M.T." throughout his 1938 book, as if trying to avoid mentioning his full name (M.T. stands for "Molnar Tibor" because in Hungarian, the Christian name is typically given after the family name). According to Chengery Pap (1930-1931), Molnar was a lanky man of only $1.59 \mathrm{~m}$ size and $47 \mathrm{~kg}$ weight. In 1930, he was 30 years old. According to Chengery Pap, he was battered by a mob during the communist riots in the late 1910s. Since then, he had been ailing constantly, and his mediumistic abilities were strong only when he was in good health. Allegedly, the first spontaneous anomalous phenomena started to occur in 1921 or 1922. Molnar stated he was frightened by them and consulted a physician who, nevertheless, considered him insane. Later, another physician familiar with psychical phenomena, a Dr. Lebök, acquainted Molnar with spiritualism, and he thus became a medium (Chengery Pap, 1930-1931).

By profession, Molnar was a painter, but he didn't seem to earn much. As a medium, Molnar was particularly known for physical phenomena and producing apports, often spontaneously and in bright light. At the beginning of séances, he typically fell into a trance and a personality named "Consuelo" spoke through him. An author who visited about 50 séances with Molnar between 1926 and 1928, Karl Röthy, described how in red light, raps and drumming sounds were heard from the table around which they sat, and how it frequently moved and levitated, even without anybody touching it (Röthy, 1928a,b,c). Molnar's hands including his thumbs were held by his neighbors, and his feet were controlled as well via body contact. When the levitated table remained suspended in a stable position, sitters sometimes tried to move it, but it seemed impossible. Similarly, János Toronyi sat with Molnar from 1925 until 1934, usually in the afternoon (Toronyi, 1951). ${ }^{3}$ The sitters would form a chain with their hands and step two meters back from the table, with nobody touching the table. Still, the table would move vividly in the space between them, and powerful raps and drumming sounds were heard that seemed to correspond to movements of the entranced Molnar's controlled hands. These phenomena endured for 


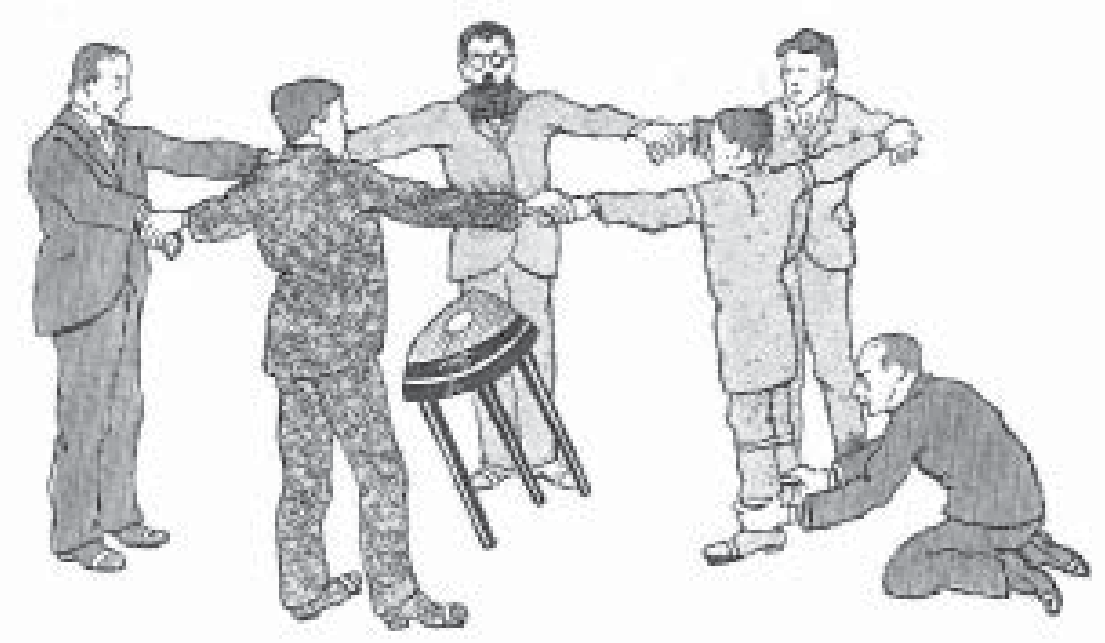

Figure 2. Illustration of supposed telekinetic table phenomena without touch mediated in 1930 by Tibor Molnar in the dark, whose ankles are controlled by Elemér Chengery Pap. The man with the beard is supposed to be Lajos Pap. The white parts of the table depict phosphorescent parts that would glow in the dark and make the table's movements visible (Chengery Pap, 1938:168).

20 minutes, and sittings were held each week for more than half a year (Toronyi, 1951, compare Figure 2). Chengery Pap (1938) reported similar experiences with Molnar. In darkness, numerous kinds of apports were brought by "Consuelo," sometimes from different rooms of the house the séance was held in, or even from surrounding houses. Apports allegedly also occurred when Molnar lay on a sofa, tightly sewn into a blanket that covered his body from his feet to his neck. In dim light, larger objects could sometimes be seen traveling through the air in inexplicable ways (Röthy, 1928a, Toronyi 1951).

When Chengery Pap began to work with Molnar in 1928, he knew him already from previous sittings. For his studies of table phenomena, Chengery Pap used two tables that were specifically designed. One table had broad and slanted side boards to hamper sitters lifting it with their fingers. Still, it levitated and produced hammer-like raps, even when nobody seemed to touch it (Chengery Pap, 1930-1931, 1938) (see Figure 2). The second table had no top, but long boards on each side (Figure 3). Therefore, thumbs and other fingers could not easily be stuck under it to lift it. The tabletop was replaced by a box that fit exactly into the hollow construction of the table's side boards, which overtopped the surface of the box by $3 \mathrm{~mm}$. It was not 

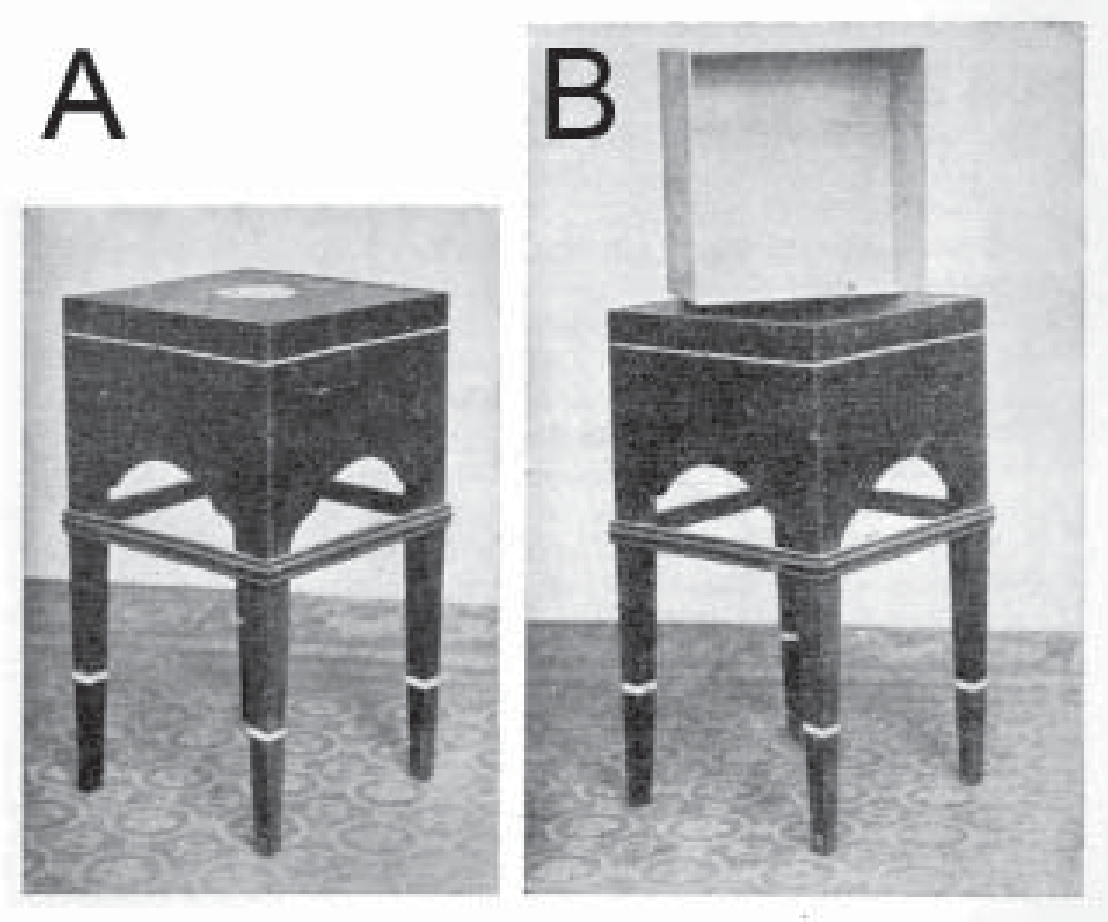

Figure 3. (A) One of Elemér Chengery Pap's experimental tables used for obtaining telekinetic phenomena.

(B) Shows the special inset of the table that was constructed instead of a tabletop. It supposedly levitated frequently out of its framing during séances (Chengery Pap, 1938:405).

possible to lift the box out of this construction with fingers when the table stood on its legs - but still it frequently levitated out of the table's scaffold during séances (Chengery Pap, 1930-1931,1938; Röthy, 1928c).

Other physical phenomena of Molnar's reported by Chengery Pap include levitations of little baskets, the stopping of the pendulum of a clock from a distance, setting it in motion again, and, most notably, numerous spontaneous apports that frequently occurred in full light. The most drastic example might have been the ostensible apport of a fragment of a gravestone that fell down next to Molnar when he entered a room Chengery Pap sat in with Lajos Pap and a regular circle member, Sándor Schürtz, at 7:15 p.m. on August 8, 1931 (Chengery Pap, 1938:425-427). This stone weighed $9.2 \mathrm{~kg}$. Perhaps the most astonishing apport reported from Molnar was the re-creation of a sealed envelope that was burned by Chengery Pap and another sitter during a séance on February 16, 1929. Chengery Pap 
specifically created three envelopes for experimental purposes in October 1928, and marked them individually in various ways, also using seals. Then the medium prompted the sitters to choose one of these envelopes, and to burn it in the oven. Consequently, the two men switched a lamp on, and chose envelope Number 2, which had additionally been marked just prior to the séance, as witnessed by several sitters. Chengery Pap and his companion thoroughly inspected it, put it into the oven, and watched it burn. Thereafter, they were supposed to collect the ashes from the oven, put it on a shovel and put the shovel on the séance table. In darkness again, Molnar spasmodically pressed the hands of the controllers next to him for some time, and eventually claimed the envelope would be present again. The light was switched on, and indeed the envelope lay on the ashes in the shovel on the table, and it was recognized by the sitters as the specimen burnt previously. Apparently, even the most minute idiosyncratic marks were present exactly where they had been before, including the mark just added before the sitting (Chengery Pap, 1938:351-368,386f; see also Chengery Pap \& Blacher, 1936; Blacher, 1937). ${ }^{4}$

However, Molnar's ability to produce physical phenomena eventually declined. The last sitting Chengery Pap held with Molnar dates to June 8, 1932. During the earlier sittings, Molnar produced only small apports such as a single coin, small pieces of plants, or even no apports at all; whereas Lajos Pap's ability to generate apports seemed to develop considerably and included more and more living animals. But, as mentioned before, Chengery Pap didn't state why he terminated his work with Molnar. Toronyi sat with Molnar until 1934 (Toronyi, 1951), and I was not able to find further information about Molnar's mediumistic activities and his life after 1934.

\section{Lajos Pap (1883-1938)}

The medium whom Chengery Pap worked with most intensively, Lajos Pap, was born on February 26, 1883. He was married, had two sons and one daughter, and worked as a carpenter. Chengery Pap (1938, pp. 130-152) described in detail how the mediumship of Lajos Pap was discovered and how it developed. Apparently, his mediumistic abilities were first noted when he participated in table séances organized by Toronyi in autumn 1922. Although Lajos Pap held a materialistic position and didn't believe in mediumistic phenomena at that time, Toronyi convinced him to join a sitting, and in his presence the table moved most violently. Lajos Pap attended more sittings, and slowly he became interested in the phenomena. In 1924, Chengery Pap first visited sittings with Lajos Pap. From autumn 1925 on, Lajos Pap entered trance states and the strength of the table phenomena increased, and the first full levitations of the table were reported. According 
to Toronyi (1951), he even moved a sofa on which three persons sat $3 \mathrm{~m}$ across the room without touching it. The first apports were noticed during a sitting held in 1927. At that time, Lajos Pap's control spirits didn't speak through him. Communication with them had to be performed via typtology, i.e. via the tilting table knocking its legs on the floor. From 1927 onward, Chengery Pap aimed at introducing more and more control conditions into the séances, and he visited Graz, London, Paris, and Munich to study physical mediums (such as Mrs. Silbert) and the methods applied by their researchers. Thereafter, he frequently invited Molnar, Lajos Pap, and 4 to 6 selected sitters to séances to be held in his own facilities, and he began to write protocols for the sittings. The phenomena of Lajos Pap were similar to that of Molnar. They included levitations of little baskets painted with phosphorescent color, the stopping of the pendulum of a clock from a distance and setting it in motion again, various luminous phenomena, and of course the production of apports.

From July 1928 on, the sittings with Molnar and Lajos Pap were held in a special room that belonged to a facility Chengery Pap rented in Budapest, where Molnar also had his atelier. The mediums and all circle members had to empty their pockets before the séances and wore luminous strips on their wrists and around their ankles to render it possible to locate their positions in the dark, especially that of their limbs. The mediums' clothes were searched, and then they slipped into a special jacket to be worn above their usual clothes. From November 29, 1930, on, Lajos Pap wore a special experimental robe without pockets during the sittings, buttoned at the back, and which was pasted with many more luminous straps. Chengery Pap aimed at creating a better-suited environment for his experimental sittings. Hence, he established a "metapsychical laboratory" on the second floor of a building at 62 Mészaros Street in Budapest; the building still exists today. On May 7, 1932, the first sitting was held in this location with both mediums (see the next section). And, finally, since a séance held in Graz on May 19, 1932 (the day after the sitting with Mrs. Silbert), the supposed control spirits of Lajos Pap - most often "Rabbi Isaac"-spoke verbally through the entranced medium, which greatly eased the communication.

In the new laboratory, Chengery Pap focused his research on studying apport phenomena. Telekinetic phenomena were also performed with small baskets painted with phosphorescent color, but the study of table phenomena was hardly attempted anymore. Still, the sitters would typically sit around a table. It bore a self-luminous plate in the middle of the tabletop, onto which apported objects would often be placed to render their shapes visible. In 1932 and 1933, Lajos Pap's ability to produce apports seemed at its best, and I will introduce some of the most remarkable incidents 
later. In 1934, Lajos Pap was invited to hold a few sittings in Sweden, and allegedly he caught a severe illness in the cold that rendered his health delicate throughout the following years, and caused recurrent outbursts of painful rheumatic symptoms (Anonymous, 1934a; Chengery Pap, 1934, 1938; Hellberg \& Kassal, 1934). Nevertheless, in 1935 Lajos and Chengery Pap responded to an invitation from the journalist, psychical researcher, and psychologist Nandor Fodor and traveled to London to hold a number of séances. Fodor had visited a séance in Budapest in 1933, and was intrigued by what he experienced (see below). At that time, the phenomena reported from Chengery Pap's laboratory had already raised the interest of numerous spiritualists and parapsychologists, and thus Lajos Pap's scheduled trip to London was eagerly awaited and announced in England (Anonymous, 1935a, 1935b, 1935c [these articles were presumably written by Fodor; see Pap, 1938, p. 550]), and the results of the first sittings were briefly commented upon (Anonymous, 1935d, 1935e). Likewise, parapsychologists in continental Europe were intrigued by the prospect that Lajos Pap would hold sittings under controlled conditions that were guided by an independent researcher. Karl Röthy, for instance, who continued to report on Chengery Pap's experiments with Lajos Pap in an Austrian journal (e.g., Röthy, 1930, 1933b, 1934b), also announced (Röthy, 1935a) and commented (Röthy, 1935b) on the course of the London sittings. In France, an announcement of the test in London was published as well (Anonymous, 1935f). However, the results achieved during the sittings in London did not convince Fodor of the genuineness of the displayed phenomena (see below).

The last séance described in Chengery Pap's book dates to January 29, 1938. In this month, typical séance phenomena with Lajos Pap were still reported, but to a diminished degree. They comprised supposed levitations of the little basket and apports of dozens of small objects, including thumbtacks, nails, and small stones. However, Lajos Pap died in 1938 (Tabori, 1951; Toronyi, 1951), but I was not able to find out more about the circumstances of his death. There is an entry about him in the Encyclopedia of Occultism and Parapsychology (Melton, 2001), but it is short and only partially correct. In any case, Lajos Pap died in the year Chengery Pap's book was published, most likely at the age of 55 .

\section{The "Metapsychical Laboratory" of Chengery Pap and the Control Measures Applied}

As mentioned, Chengery Pap established his "metapsychical laboratory" on the first floor of a building in Budapest, and held the first sitting there on May 7, 1932 (Figure 4). The main experimental room was joined to the anteroom for examining the mediums and the sitters' clothes and bodies, 


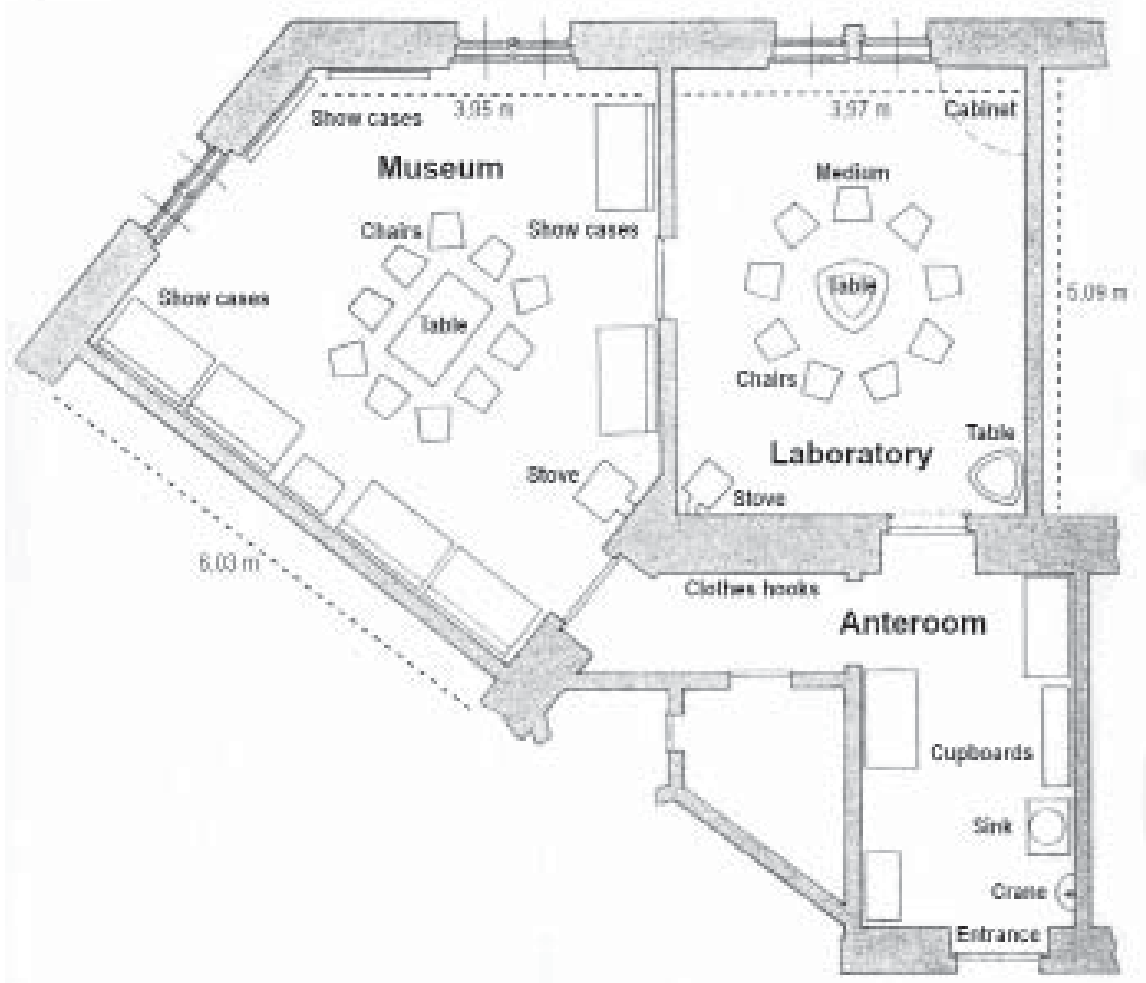

Figure 4. Floor plan of Elemér Chengery Pap's Metapsychical Laboratory in Budapest with its museum and anteroom (after Chengery Pap, 1938, p. 153, see also Chengery Pap, 1938, p. 205).

and by a room in which an "apport museum" was installed to show all the objects that were ostensibly apported by the two mediums during séances as well as spontaneously since 1928 (Figure 4, Figure 5). However, Molnar participated in only the first three sittings in the new laboratory. After June 18, 1932, all sittings were held with Lajos Pap as the only medium present.

The sittings in this laboratory were usually held in the evening and in intervals of every two weeks. Prior to the sittings, everybody had to empty their pockets. Only a handkerchief was allowed into the séance room and that needed to be inspected beforehand. Then two sitters whose pockets had already been checked, usually the guests, entered the laboratory to inspect its interior. They locked the wooden door leading to the museum, and locked a wire mesh door that was mounted in front of the solid wooden 

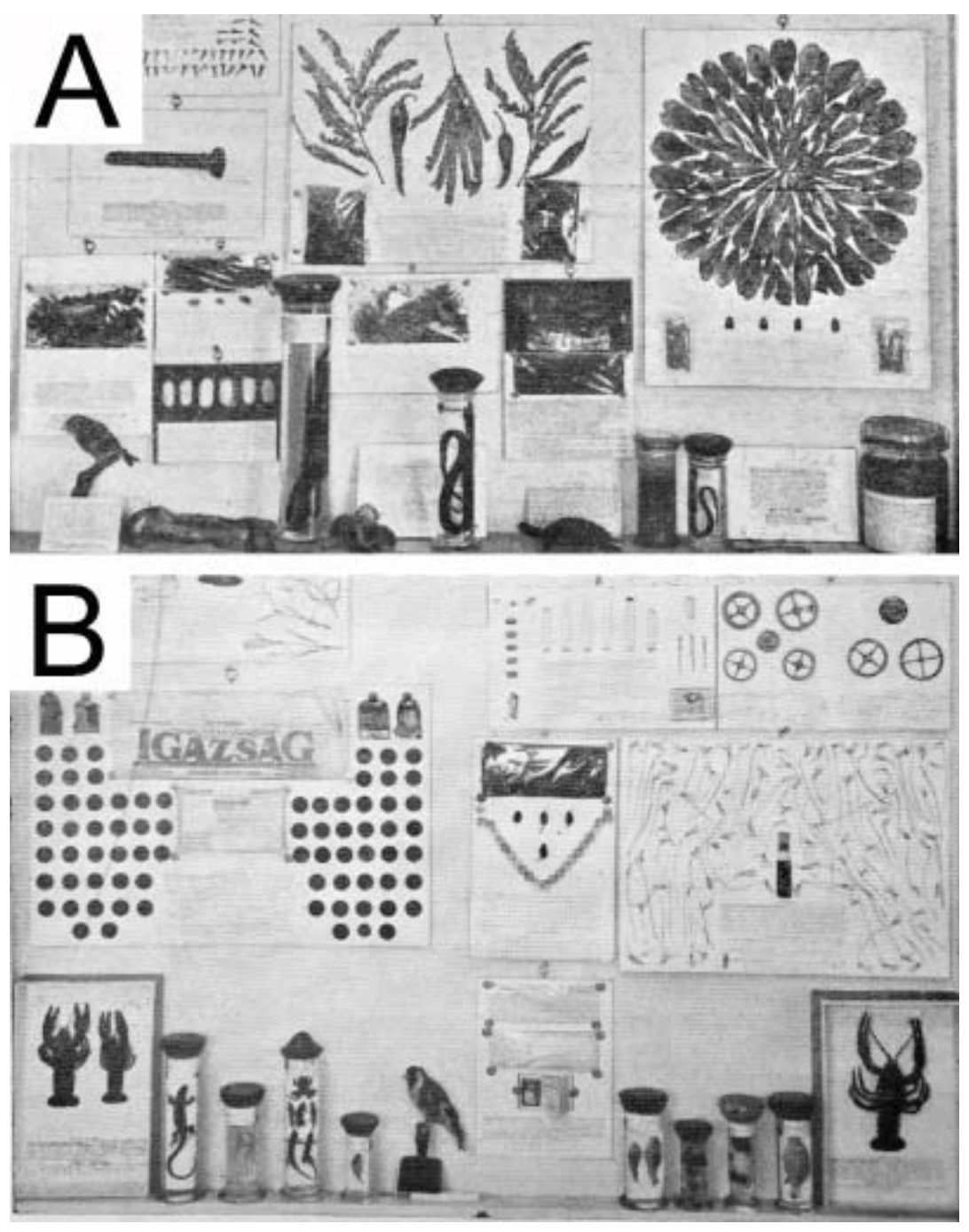

Figure 5. Examples of the apports exhibited in show cases in Elemér Chengery Pap's apport museum.

(A) Some apports received via Lajos Pap in 1933 and 1934 (Chengery Pap, 1938, excerpt of Plate XXIX).

(B) Some apports received via Lajos Pap in 1934 and 1935 (Chengery Pap, 1938, excerpt of Plate XXX).

At the bottom of Figure $5 \mathrm{~A}$ and Figure $5 \mathrm{~B}$, larger animals, such as birds, fish, reptiles, amphibians, crayfish, etc., are displayed. 
door that led from the laboratory to the anteroom. The mesh width of this door was $2 \times 6 \mathrm{~mm}$, and it could be locked and unlocked only from inside the laboratory. At times, the controllers were accompanied by Chengery Pap who assisted their controls and searches. After entering the main room, they first controlled each other, and thereafter, they carefully examined the floor, the walls, and the ceiling of the laboratory which were painted a whitish color and had no interstices. All objects in the relatively empty room needed to be scrutinized as well: There were two tables (one in the corner was for reserve), several chairs, the cabinet curtains (nobody ever sat in the cabinet), lamps on the walls and one on the ceiling, a clock on the wall, and a few smaller items such as a small basket and phosphorescent plates, the séance dresses of the circle members, etc. The other sitters observed the controllers' activities from behind the locked wire mesh door.

Next, Lajos Pap was let into the room and was carefully searched. He typically undressed the upper part of his body, and the controllers felt his lower body parts down to his shoes. Sometimes, he also lowered his trousers and underpants down to his knees to be inspected in the groin area. In case women watched the control procedure from behind the mesh door, they were asked to leave their place at the door for this part of the examination. Lajos Pap's clothes, pockets, hair, beard, mouth, ears, etc., were searched as well. Chengery Pap often stressed that he was searched from "tip to toe." Thereafter, he was dressed in his scrutinized, one-piece experimental robe, which needed to be closed with buttons at its back. From December 1936 on, this robe was additionally closed with a zip fastener at the back, and he wore spats at his feet that girded the trouser ends of this dress.

When the examination of Lajos Pap was finished, the other séance participants entered the laboratory one after the other, always being checked and patted down. The women were controlled by one of their number. All participants had to wear luminous strips around their wrists and ankles. From October 7, 1933, on, all regular sitters wore séance robes similar to that of Lajos Pap on which the luminous strips were sewn-with the curious exception of Lajos Pap's wife, who often participated in the séances (Chengery Pap, 1935; see also Figure 6). From December 1936 onward, their dresses were furnished with an additional zip fastener on the back as well. The keys of the locked doors were usually kept in the pocket of the guests who locked the doors. Only when all sitters were satisfied with the performed controls was the sitting allowed to begin. Chengery Pap appointed the persons who were supposed to control Lajos Pap, as well as the order of the sitters. All sitters were instructed to form a chain with their hands that was never to be broken, and in case somebody needed to break the chain for whatever purpose (for example, to control the medium in the 


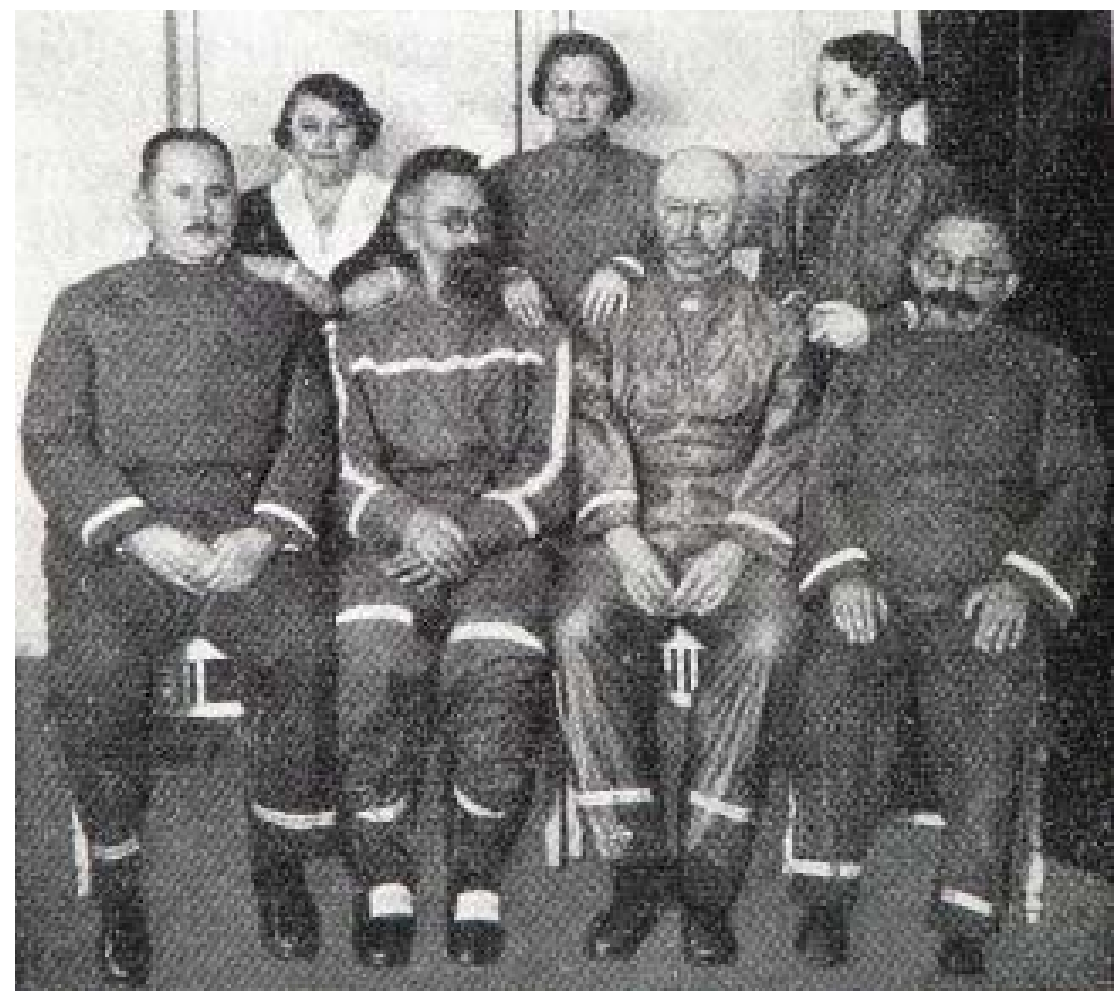

Figure 6. Group photograph of the regular circle members in October 1933.

Front row, left to right: Reszö Groh (physician), Lajos Pap (medium), Elemér Chengery Pap (circle leader), and Sándor Schürtz (bank director). Back row, left to right: The wife of Lajos Pap, Piroska Janovitz (physician), and Erzsébet Schürtz (student of philosophy).

The photo was taken in the séance room; on the right side in the background, the cabinet curtain is visible (Chengery Pap, 1938, p. 139).

course of the sitting), the hands of the neighbors needed to be closed by this person before the chain was opened. After the light was switched off, the room was still dimly lit by a number of phosphorescent items that glowed in the dark. Most importantly, Chengery Pap mounted 10 luminous boards of about $25 \times 30 \mathrm{~cm}$ to the walls and doors of the séance room. Other luminous items included the lampshade above the experimental table, boards on the two tables in the room, the little luminous basket, and the luminous straps on the clothes and bodies of the sitters. Allegedly, all these phosphorescent items allowed for perceiving the outlines of the sitters in the dark quite distinctively, comparable to sitting in moonlight—at least at the beginning 
of the séance. The postures of the sitters were indicated by the luminous bands anyway. From October 3, 1936, on, several infrared photographs were taken during the séances as well.

The composition of the few circle members who regularly sat with Chengery and Lajos Pap from 1928 on was relatively stable. In 1932, they consisted of physicians Dr. Rezsö Groh and Dr. Piroska Janovitz, the director of the Hungarian Central Savings Bank Sándor Schürtz, and Erzsébet Schürtz, a student of philosophy (most likely the daughter of Sándor Schürtz, whose wife also attended four sittings). In addition, the wife of Lajos Pap frequently joined the sittings. Of the 194 séances held with her husband between 1928 and 1938, she was present on 91 occasions. These circle members are shown in Figure 6. In the summer of 1934, Piroska Janovitz and Erzsébet Schürtz ceased visiting the séances, but a retired chief financial auditor of Budapest, Dömötör Kornya, who had already frequently sat with the circle as a guest, became a regular member. However, not all members were present at each sitting. In addition to the regular circle members, Chengery Pap invited one to three guests per sitting to demonstrate the occurring phenomena-similar to the demonstration sittings that Albert von Schrenck-Notzing held in Munich with medium Willi Schneider (Schrenck-Notzing, 1924a). According to a list included in his book, 210 different guests of predominantly the higher social strata visited séances headed by Chengery Pap between 1928 and 1938.

Until 1931, a gramophone was often operated during the sittings by grammar school pupil János Kürtös. Thereafter, Kürtös, who later attended a business school, only participated in a few sittings until 1936. In the new laboratory, he operated a gramophone on only a few occasions. It was either mounted in the locked museum or in the anteroom. In the latter case, the main door that lead from the anteroom to the laboratory was left open, but the wire mesh door was locked. In the later years, music was hardly employed. From September 1936, Kürtös wrote real-time, shorthand protocols describing the events that occurred during the séances in the anteroom, again sitting behind the locked mesh door. The main door was left open to better understand the dictates of Chengery Pap from within the laboratory. Previously, notes of the occurring phenomena and events were taken down in shorthand following verbal descriptions, but I was unable to find more information about how precisely this was achieved.

In the next section, I summarize some of the most astonishing phenomena reported from Lajos Pap. Since apport phenomena were his specialty, I will focus on them. The reported telekinetic and luminous phenomena also were impressive, but didn't differ much from those of other physical mediums. Moreover, I will focus on sittings held in the metapsychical laboratory. 


\section{Remarkable Apport Phenomena Reported on Lajos Pap}

Although most of the apports from Molnar and Lajos Pap were received during sittings, numerous objects also seemed to appear spontaneously during ordinary circumstances of daily life. Spontaneous phenomena with Lajos Pap were not as frequent as with Molnar, but Chengery Pap was obviously impressed by some of them. For example, when he and Lajos Pap were walking in the middle of an empty area in front of a depot in Budapest on the afternoon of January 1, 1933, five snowballs hit Lajos Pap's coat from behind. However, nobody else was to be seen at this location, and the windows of the nearest houses were at a considerable distance and closed. Moreover, these balls were not compacted like those formed by hand, but were scoops of snow that looked like the nearby snow that was perhaps "thrown" (Chengery Pap, 1938, p. 141).

\section{Apports from Distant Locations and from within Locked Containers}

Some of the apports received during séances in the laboratory concerned objects that appeared to originate from locked spaces. For example, during a sitting in the laboratory on May 16, 1936, Lajos Pap seemingly snatched a paper sheet in the air with his right hand and gave it to Chengery Pap, the séance leader. In the following break from the sitting, this paper was identified as a document that belonged to Chengery Pap and was usually stored inside a locked cupboard in the latter's home (Chengery Pap, 1938, pp. 145, 504). On occasion, Lajos Pap also apported objects from the anteroom or the museum into the locked séance room of the laboratory. For instance, toward the end of a sitting held on October 3, 1936, two rectangular pieces of cardboard fell onto the phosphorescent and luminous disc on the experimental table in the séance room when Lajos Pap held his hands above it while controlled by neighboring sitters. The entranced medium switched the light above the table on, and these two pieces of cardboard turned out to be specimens that were originally created by Chengery Pap for experimental purposes in 1930. One was green and one was cream-colored, and both were signed with Chengery Pap's private seal and his handwriting. They originated unmistakably from an envelope that was usually stored in a locked cupboard in the anteroom. However, "Rabbi Isaac" informed the sitters that this envelope was to be found in a pocket of the coat of a guest sitter, Mr. Verubek, left in the anteroom. He turned the light out again, and ended the séance several minutes later. Indeed, the uniquely marked envelope was later found in Mr. Verubek's coat's pocket. It seemed untouched, but the two cardboard pieces were not inside it any more (Chengery Pap, 1938, pp. 334-341, 512). On January 27, 
1934, Lajos Pap even apported a living turtle from the anteroom into the séance room. At one point, he asked his controlling neighbors to squeeze his wrists as hard as possible, "breaking" his bones. Thereafter, he covered the luminous plate on the tabletop with both hands, the wrists still being held by the controllers. When he removed them again shortly after, a small living turtle sat on the plate. The sitters knew that a turtle of this size lived in a terrarium in the anteroom, and indeed it turned out that it was missing from there. Since the initial controls of the séance room were performed and all the participants entered it about two hours before, the doors to the séance room had constantly been locked from the inside, the keys being in the possession of two guest sitters (Chengery Pap, 1938, pp. 145, 299-302, 481). The turtle, by the way, had initially been apported in a comparable manner during a séance on July 29, 1933. After performing a number of "automatic" movements (see below), Lajos Pap approached the luminous plate with both hands, and after he removed them the turtle sat on it. It weighed 41 grams.

\section{Wish Apports and Announced Apports}

Sometimes, Lajos Pap also reacted to requests from Chengery Pap and provided "wish-apports." For example, he once apported 197 maize kernels after Chengery Pap asked him to bring maize kernels for one of the guests into the séance room (sitting on November 19, 1932). On another occasion, he asked Lajos Pap to bring some bell pepper. "Rabbi Isaac" agreed, but jokingly added that he would rather put it into the upper pocket of Schürtz's coat in the anteroom, because he feared that the vegetarian Kornya would immediately eat it if brought into the séance room. Indeed, Schürtz found bell pepper in the appointed pocket of his coat after the séance (sitting on October 6, 1934).

Sometimes, and at the request of Chengery Pap, "Rabbi Isaac" also announced days or weeks in advance what kinds of apports he would bring at a given séance to prepare the controllers for what they should look for during their examinations and to allow Chengery Pap to prepare the appropriate containers for living animals. For example, he announced he would bring apports of a mouse, birds, and other animals at certain future séances, also liquids, and these creatures and substances were duly apported.

\section{Apports of Liquids}

One of Lajos Pap's specialties was apporting liquids of various kinds. They included evil-smelling hydrosulfide, but also drips and small amounts of fragrant perfumes as well as larger amounts of water, wine, beer, apricot 
liquor, coffee, cream, or honey that were usually collected in empty bottles during the séances. The mode in which the liquids were received was always similar. For example, at a sitting during the night of New Year's Eve 1932/1933, Lajos Pap apported about half a liter of wine. After he fell into a trance, "Rabbi Isaac" announced he would bring some red wine, asked for an empty bottle, took it in both hands, performed various movements with his hands (which were controlled at the wrists), turned around and stepped on his chair (the controlling neighbors also got on their chairs), and held the bottle above his head. He began to swing it up and down with both hands, and the smell of wine was perceived in the room. After a few minutes, he handed the bottle to Chengery Pap, claiming that it already contained wine. When the latter held the bottle above the luminous disc on the table, about $20-30 \mathrm{~cm}^{3}$ of wine seemed indeed to be inside the bottle. "Rabbi Isaac" asked for the bottle again, held it up again with both controlled hands, and a few seconds later repeated milking sounds were heard, and the smell of wine increased. After some minutes, the medium carefully passed the bottle back to Chengery Pap, stating that it would be full. Indeed, it was filled to the brim. The wine apport lasted for about ten minutes. When the light was switched on, the wine turned out to be a kind of rosé (Chengery Pap, 1938, pp. 221-224, 461).

On December 16, 1933, Lajos Pap apported among other objects numerous very cold drops of water-and even snow. Chengery Pap considered the snow apport one of the most evidential apports received, as it occurred about 2 hours after the séance begun, and at a rather constant room temperature of about $22{ }^{\circ} \mathrm{C}$. Prior to the sitting and before Lajos Pap had entered the trance state, Chengery Pap asked him to bring some snow from outside into the séance room. After a break that lasted from 9 to 9:25, the locked laboratory was inspected again, and the medium and sitters searched when they entered the room one by one. A few minutes later, Lajos Pap stood up from his chair, turned around, and stood on his chair; his neighbors climbed on their chairs, holding his wrists. He moved his arms up and down and asked his controllers to fiercely press his wrists. At 9:40, he snatched something out of the air with his right hand, and gave it to Chengery Pap. It was a compressed piece of snow of the size of a hazelnut. The séance leader put it into an empty bottle. Within the next ten minutes, this procedure was repeated eight times. Thereafter, the medium announced that he would sprinkle the sitters with cold water, and indeed the sitters, the table, and the floor were splattered with numerous ice-cold drops of water. When the snow in the bottle thawed, the sitters noted a peculiar smell and pieces of horse dung in the muddy water inside the bottle. "Rabbi Isaac" triumphantly remarked that he would hardly be able to swallow and regurgitate snow, in 
particular snow of this kind. Given the seemingly rigid controls of the sitters and the laboratory, regurgitation was apparently deemed the only possibility left for producing fraudulent apports. After the sitting, a small puddle of this dirty water was also found on the floor behind Lajos Pap's chair (Chengery Pap, 1938, pp. 290-293, 476f; see also Chengery Pap, 1935). Similarly, when he apported $140 \mathrm{~cm}^{3}$ of honey into a bottle on December 2, 1933, honey was also found on the floor where the medium stood.

On three different occasions the medium even apported considerable amounts of water and living goldfish. At the first two séances, they were received in the typical manner of apporting liquids. Lajos Pap would stand on his chair in the dark, hold the bottle in the air with both hands, ask his neighbors to tightly squeeze his wrists and "break" his bones, and liquids would then be poured into the bottle. On July 7, 1933, he apported several living caterpillars, 12 dead dragonflies, and two small goldfish. On August 26, 1933, he apported 7 pebbles, 16 living locusts, 12 living butterflies, and two more goldfish. Lastly, after he apported several other objects on December 2, 1933, he first apported water that contained pieces of algae into a bottle. Then, he seemed to snatch a 8-cm long, fidgeting goldfish from the air and gave it to Chengery Pap who then put it into the bottle with the apported water.

\section{Apports of Animals}

As stated previously, Lajos Pap's most celebrated mediumistic ability was the apport of animals, and, like the already-mentioned turtle and fish, they were often still alive. Yet, this was not always the case, and occasionally "Rabbi Isaac" apported dead animals on purpose. For example, at a sitting on November 4, 1933, he apported among other items 21 locusts that had obviously been dead for some time before they were apported. Chengery Pap suggested that they constituted an allusion to the military relations of one of the guest sitters. On June 16, 1934, he snatched something from the air and put it into Chengery Pap's hand. The object smelled dreadfully and turned out to be the decomposing cadaver of a little bird. The medium claimed he apported it to demonstrate that he didn't regurgitate the apported objects. Apart from living beetles and flowers, a dead and a living bird were apported on April 22, 1933. Such larger animals were often apported in the small basket. After the break for this séance, Lajos Pap was carefully searched again by a circle member, and he let the little basket be searched as well. He then took the basket in his hand, stepped on his chair, as usual followed by the controllers, and waved the basket up and down. The medium began to whistle and stated that he would attract a bird now. After a while, he asked the controllers to squeeze his wrists, then moved back to the table 
(it was 8:34 p.m.), and emptied the basket carefully above the luminous disc. A seemingly dead songbird fell from the basket. It was already cold. Chengery Pap complained that he promised to bring a living bird, to which "Rabbi Isaac" replied that he would revive it. He grabbed the bird from the table and threw it against the opposite wall, where a muffled impact was heard. He took the basket again, performed the usual movements on his chair while his wrists were held, and at 8:44 he returned to the table. He covered the opening of the basket with one hand, passed it to Chengery Pap and asked him to carefully fetch the bird from it. The latter cautiously reached into the basket between its rim and the medium's hand, and indeed he was able to grab a living bird that clutched to one side of basket. It was put in a box and turned out to be a goldfinch (Carduelis carduelis). The dead bird that was seemingly apported before was not found during the post-sitting searches (Chengery Pap, 1938, pp. 231-237, 466f). A second goldfinch was apported on May 20 of the same year. This time, Lajos Pap held it directly in his hand and gave it to Chengery Pap. It was in a torpid state, but it recovered soon. The first finch lived in the museum until April 24, 1934; the second until January 13, 1936.

The other animals apported by Lajos Pap were usually received in a similar manner. Either they appeared inside the basket, or they were directly handed over to Chengery Pap and others from out of Lajos Pap's hands while he appeared to snatch them from the air. Living vertebrate animals apported in these ways included three more turtles (one weighing 215 grams), songbirds, snakes, lizards, frogs, a newt, mice, and, most notably, a living sparrow hawk. Toward the end of a sitting held on December 30, 1933, "Rabbi Isaac" announced that he was about to bring an eagle. He stood on his chair, was controlled at his arms as usual, asked his neighbors repeatedly to firmly squeeze them, and moved them up and down with the basket in his hands. Several times, he turned around and seemed to put something into Chengery Pap's hands, but they remained empty. At one point, however, Lajos Pap grabbed something in the air, gave it to Chengery Pap who put the object onto the luminous cardboard on the table. It was an apparently lifeless bird of considerable size. Yet soon it began to move, and was put into a parrot's cage that Chengery Pap had brought into the laboratory as Lajos Pap had already announced that he would apport a large bird one day. The bird came fully to itself. It turned out to be a sparrow hawk, and it lived three more days (Chengery Pap, 1938, pp. 293-299, 477). Yet, not all vertebrates were apported alive, or survived the process of being apported. Lajos Pap also apported a dead squirrel that was still warm and had live fleas on its body, and two dead snakes.

Similarly, some of the invertebrates that decorated Chengery Pap's 
apport museum were apported alive, some dead. The most remarkable apported living invertebrates include seven crayfish that appeared during six séances between 1933 and 1937. The largest specimen measured $12.7 \mathrm{~cm}$ from the tips of its tail and head, excluding the considerably protruding claws and antennae. In other noteworthy séances, astounding amounts of insects were apported in addition to other objects and plant pieces such as flowers, leaves, fruits, or entire twigs. For example, at a séance on August 27, 1932, Lajos Pap apported 30 butterflies, tipping the basket over the luminous cardboard on the table. Four of them were still alive. Moreover, he apported six live and four dead locusts, one living dragon fly, and three other insects. During a sitting on July 15, 1933, Lajos Pap apported six living and nine dead butterflies from out of the basket, as well as seven living and six dead other kinds of insects such as different beetle species and a locust. Most notably, he also apported 15 male stag beetles. As usual, he stood on his chair with the back to the circle, moved his arms up and down, asked the controllers to press his wrists and "break" his bones, and snatched the stag beetles from the air, one after the other, carefully handing the protesting individuals down to Chengery Pap who collected them in a container on the table. The apport of the 15 stag beetles took place within seven minutes (Chengery Pap, 1938, pp. 251-253, 741f; see Figure 7). At the previous séance briefly summarized here, the already-mentioned Hungarian psychical researcher Nandor Fodor participated as a guest sitter. Although he needed to leave the sitting held on June 3, 1933, during the second break, the phenomena he witnessed during the first two parts of the sitting greatly impressed him. The first part chiefly consisted of telekinetic phenomena during which the little luminous basket moved in various ways through the séance room, seemingly by itself and while Lajos Pap was controlled at his arms. After the first break was over, Fodor and another guest searched and controlled the laboratory as well as the medium and the other sitters as they entered the room. The doors were locked from the inside. Shortly after, Lajos Pap fell into trance again in the darkened room. In the dim light of the many phosphorescent plates and objects, "Rabbi Isaac" asked Fodor again to examine the medium. He didn't find anything suspicious, and thereafter the medium announced he would bring in 30 animals that would most likely be rose chafer beetles. At 9:34, he turned around, stepped on his chair, asked his controlling neighbors and also Fodor to examine his hands (they found nothing), and immediately after that he asked them to press his wrists so hard that his bones would "break." At 9:35, he snatched something from the air, and passed a small fidgeting animal to Chengery Pap. It was a rose chafer. These activities went on until 9:45; Fodor and the other sitters also received rose chafers directly from Lajos Pap. They collected them in a 


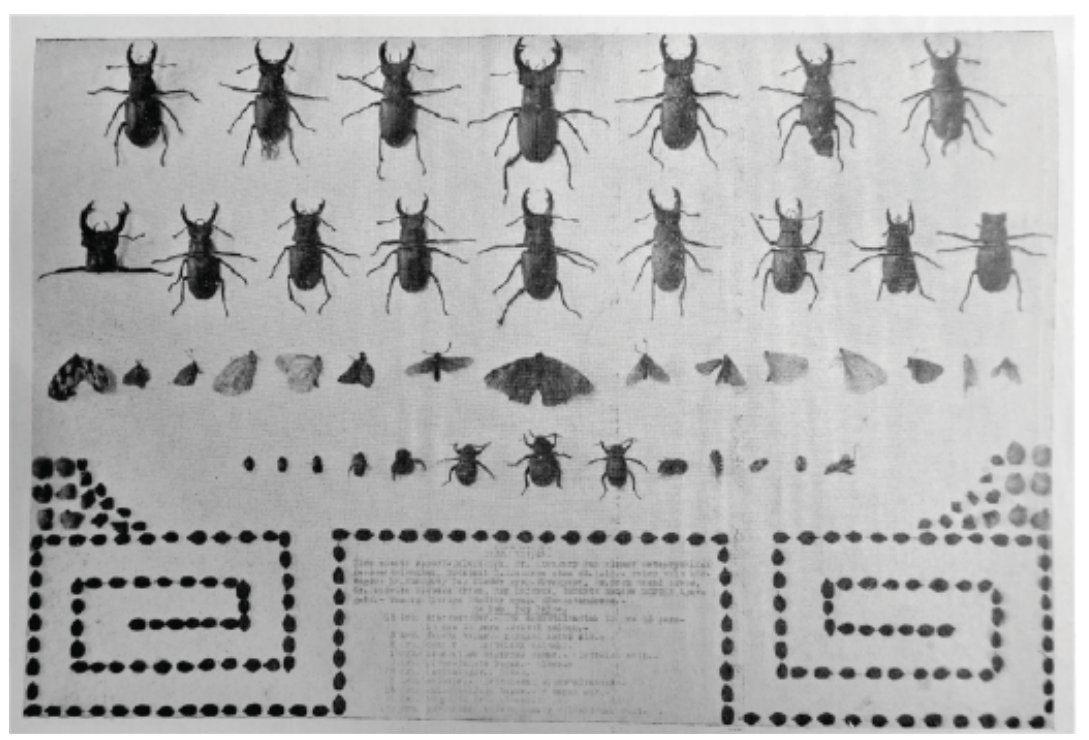

Figure 7. The apports received via Lajos Pap at the sitting on June 15, 1933, as they were exhibited in a show case in Elemér Chengery Pap's apport museum. In addition to 31 berries, 201 plant seeds, and several other insects, Lajos Pap apported 15 living stag beetles. The original measurements of this collage are $50 \times 33 \mathrm{~cm}$ (Chengery Pap, 1938, Plate XVI).

bottle that stood on the luminous plate on the table, and indeed they were 30 individuals. Thereafter, Lajos Pap picked up the basket, performed different kinds of movements with it, and in total, poured 29 more living beetles of a smaller species into a transparent box. Moreover, he apported three small butterflies. Finally, before the second break, he also snatched four fragrant inflorescences of acacia flowers from the air. During the third part of the sitting, after Fodor had already left, the medium furthermore apported various parts of dog roses and a stingy, 10-cm long cactus with roots, as well as bits of earth to plant it in (Chengery Pap, 1938, pp. 237-246, 469; Fodor, 1933, 1936?).

As shown in this section, some of the most remarkable phenomena attributed to Lajos Pap's mediumship apparently seemed to occur under rather strict conditions of control, and some of them, such as the wish apports, apports of snow, living crayfish, a living sparrow hawk, and more than 60 insects, flowers, and a cactus during one séance, etc., appear difficult to stage under the prevailing conditions. Not surprisingly, the reported phenomena attracted the attention of numerous people interested in 
psychical matters, and outside Hungary articles about them were published in spiritual or parapsychological journals in Austria (Röthy, 1930, 1933a, 1934a), Germany (Margittai, 1933; Sünner, 1934), France (Anonymous, 1934b), The Netherlands (van Gorcum, 1936a, 1936b), and of course England (Anonymous 1934a, 1934c; Fodor, 1933, 1934). However, these articles were unduly short, written in a popular style, and provided not enough details for forming an appropriate opinion on the control measures applied. The only source that provided these details was Chengery Pap's book (1938). Consequently, its publication was welcomed in Austria (Röthy, 1938; Walther 1938), Germany (Anonymous, 1938a), and France (Anonymous, 1938b), but it was typically also regretted that its Hungarian language rendered it practically inaccessible. Be that as it may, Chengery Pap's (1938) treatise constitutes an impressive piece of work, parts of which seem almost "too good to be true." Hence, a consideration of the opinions of other researchers regarding the mediumship of Lajos Pap and a more critical look at Chengery Pap's experiments with him seem apt.

\section{A Critical Perspective on Chengery Pap's Experimental Approach}

Apart from some of Chengery Pap's treatises, especially his book, I am aware of only one other source that contains detailed reports of a number of sittings held with Lajos Pap. It is written by the already-mentioned, Hungarian-born Nandor Fodor, who moved to London in 1929. Fodor was very impressed by the reports about Lajos Pap's mediumship, especially by the phenomena he witnessed in person during the séance he visited in the laboratory of Chengery Pap in 1933 (see above section). After his return to London, Fodor approached people who might potentially be interested in inviting Lajos Pap to London to witness and test his mediumship. However, due to the Swedish adventure of Lajos Pap in 1934, the resulting health trouble, and other obstacles, this project was only realized in May 1935. In an announcement of this visit, it was stated that the main purpose of the experimental sittings was two-fold: "(1) to establish apports as facts, if phenomena are forthcoming; (2) to determine the origin of the apported objects" (Anonymous, 1935b). Lajos Pap was accompanied by Chengery Pap. They arrived in London on May 3, and between May 7 and June 7 the medium gave ten sittings for a varying group of guest sitters under the auspices of Fodor's International Institute for Psychical Research. The experimental room in London was prepared to resemble the laboratory in Budapest as closely as possible; also, séance robes that mirrored those in Budapest were fabricated and provided. Yet, the obtained results were 
disappointing. Lajos Pap's conduct proved to be suspicious in several respects, and regarding certain phenomena Fodor even discovered outright fraud. Fodor's report of the séances is also little-known, but it constitutes an illustrative masterpiece of meticulous research into physical mediumship. It is intriguing how he uncovered more and more astonishing loopholes in Chengery Pap's approach that are not apparent in the latter's publications, including his 1938 book. I highlight some of the most peculiar issues in the following.

\section{Lajos Pap's Kidney Belt}

Fodor's (1936?) report of the sittings conveys several details that relativize some of the seemingly well-conducted experiments of Chengery Pap. This is particularly true for the latter's frequent assertion that Lajos Pap was routinely searched "from tip to toe" before each sitting and after the breaks. Fodor's most important finding was that Lajos Pap wore a kidney belt made of soft cloth beneath his shirt and séance robe. Curiously, Chengery Pap and other members of his circle didn't even inform their guest sitters about the presence of this kidney belt. It was merely discovered by chance. For example, when Fodor felt Lajos Pap all over the body in Budapest in 1933, he didn't feel the kidney belt, and was thus not aware of its existence. Similarly, the examiners who searched Lajos Pap in his clothes before the first three sittings in London were not aware of the presence of this belt. Before the first sitting, it was deliberately planned to allow the medium to wear his clothes during a cursory body examination to make him feel as comfortable as possible. Yet, no apports appeared. Before the second sitting, however, Lajos Pap complained about a bronchial cold, and refused to take his clothes off. Now, a thin dead snake of a South-Eastern European species and a pebble were apported. Fodor, assuming that the snake might have been hidden in Lajos Pap's clothes, recommended that the examiners should perform more thorough controls in future. Nevertheless, when Lajos Pap was to be searched more carefully before the third sitting, he refused the request to take off his clothes again, even though it was agreed upon during the arrangements for the sittings that he must take them off when requested. Yet, he allegedly feared that he would catch a cold in the $17^{\circ} \mathrm{C}$, warm séance room if he would briefly undress himself-but because this excuse was not acceptable, he then defended himself by purporting that his undergarments were not clean and that he was ashamed of exposing them. In that sitting, 44 rose petals and two small green leaves were apported.

Only before the fourth sitting did Fodor discover that Lajos Pap wore a kidney belt, when he undressed Lajos Pap to let him be scanned with an 
X-ray machine to rule out the possibility that Lajos Pap swallowed objects he might regurgitate during the séances (Fodor, 1936?, 1959). Lajos Pap freely admitted that he wore this belt all the time since 1932, also during séances, as he had lowered kidneys that required this external support to keep them in their position. Nevertheless, Fodor considered Lajos Pap's kidney belt highly suspicious, and he didn't even consider it as being a proper medical kidney belt. Moreover, after the X-ray examination was performed, Fodor stated the scans showed that Lajos Pap's kidneys were not lowered. This suggested that in reality, Lajos Pap didn't have kidney problems, and that the belt might serve different purposes, such as providing a hiding place for supposed apports (Fodor, 1936?).

Because of these suspicions and the further disappointing development of the London sittings, Chengery Pap (1938) went into considerable detail to describe the reasons for the kidney belt and the circumstances under which it was obtained. Allegedly, Lajos Pap complained about pain in the kidney region first in March 1932, and following the advice of Chengery Pap he was examined at the urological department of the (New) Saint John's Hospital in Budapest. The physician diagnosed a lowered kidney on the right side, and asked him to let himself be examined again in two to three months in case the pain hadn't ceased by then. The pain didn't cease, and consequently Lajos Pap visited the hospital again on June 15, 1932, accompanied by Chengery Pap. This time, the examination included an X-ray scan that confirmed the diagnosis: lowered right and left kidneys, blood in the urine, and especially the right kidney was sensitive to pressure. Thus, the physician now prescribed Lajos Pap a kidney belt that was to be worn constantly. The next day he bought such a belt and began to wear it. After two weeks, the pain had considerably decreased. Chengery Pap reprinted the written diagnoses by the hospital physicians who examined Lajos Pap. He also described how Lajos Pap was examined again in the (New) Saint John's Hospital on August 26, 1936. In contrast to the X-ray examination performed in London, when Lajos Pap removed the belt immediately before being scanned, he had to remove the belt $48 \mathrm{hr}$ prior to the scan to let his kidneys move to their natural position. As a result, physician Dr. László Hencz found that the right kidney was still lowered, enlarged, and pressure-sensitive, and he recommended that Lajos Pap should continue to wear the belt.

But, even if all this were true, it is obvious that contrary to Chengery Pap's claims, Lajos Pap's clothes and kidney belt were not properly searched before each sitting. Rather, the medium often left at least a shirt on for the search, and neither Chengery Pap, Lajos Pap, nor any other circle members informed the examiners and guests that there was a belt beneath the medium's 
shirt. It seemed to remain unnoticed by them. Yet, the wearing of such a belt is obviously so important that a routine examination of it should have been absolutely obligatory. It is especially suspicious that Lajos Pap didn't take it off even briefly. Apparently, this must have been feasible, since he took it off briefly in London for the X-ray examination. Moreover, Chengery Pap claimed that it needed hours to let Lajos Pap's kidney sink to its lowered pathological condition, so it really should have been no problem to take the belt off for, let's say, one or two minutes. It is difficult to understand why Chengery Pap didn’t insist on such a belt control.

Moreover, it is suspect that Lajos Pap began to wear the kidney belt almost at the same time as the new metapsychical laboratory was opened in May 1932 and the control conditions were tightened. The first living animals were apported by Lajos Pap at the second sitting in the laboratory, when Molnar was also present. The third sitting held in the new laboratory dated to June 18, 1932, and on this occasion Lajos Pap must have worn his kidney belt for the first time. It was also the last sitting that Molnar attended. Was all this just a coincidence? Chengery Pap didn't say a word about it. He didn't even mention the kidney belt before Fodor drew attention to it, and, as mentioned, he also didn't explain why he broke relations with Molnar.

\section{"Automatic" and Other Movements of Lajos Pap during Séances}

Furthermore, Lajos Pap's mediumship was peculiar in that when he was in trance he performed all sorts of large-scale movements with his limbs and body. Until June 1932, he used to walk a lot around the séance room, dragging the neighbors who held his wrists and consequently the entire circle with him. This was fatiguing, and of course it impeded the controls (Chengery Pap, 1938, p. 149). Hence, in the new laboratory, Chengery Pap insisted that this walking habit was to cease. He succeeded - but now Lajos Pap performed numerous "automatic movements," as Chengery Pap termed them. Specifically, he waved and swung his arms to and fro, up and down, and performed scooping or gathering movements on the floor, often holding the little luminous basket in his hands. Moreover, he frequently stepped up and down from his chair, turned around, facing the wall instead of the circle and its members. Quite peculiarly, at the end of sittings, Lajos typically left the chain of sitters, turned his back to the sitters, and "demagnetized" himself in this position all by himself. In his protocols, Chengery Pap duly mentioned these movements when they occurred. Moreover, he usually conveyed the notion that Lajos Pap was easy to control when he moved, and that the controls of his wrists were continuous and uninterrupted throughout the séances. In his first brief report, Fodor (1933) supported this notion. However, according to other authors and also Fodor's (1936?) report on 
the London sittings, this was apparently not always the case. In a report of a sitting that Theodore Besterman visited in the flat of Toronyi in 1928, he described vividly how Lajos Pap, who had allegedly been a wrestler in his youth, tried to free his arm from Besterman's controlling grip around his left wrist:

After he had repeatedly tried and failed to pass off my left hand on the left controller as his own (the medium's) left hand, he began, and continued for about five minutes, a series of most violent contortions and constrictions of his massive hands. The controller of the medium's left hand simply let it go, and I myself, in order to retain control, had to rise and circle around the medium. On this Papp [sic] redoubled his extraordinary convulsions. [. . .] My own hand, at any rate, was stiff and sore for two days afterward. (Besterman, 1929, p. 462)

Mrs. Eira Hellberg, who organized Lajos Pap's journey to Sweden in 1934, described his behavior during the sittings as follows (my translation):

Papp [sic] has the bad custom of standing up during the séance, turning himself around in circles with his whole body, bending and fidgeting, waving with a small and empty chip basket in the air, lowering himself suddenly and sweeping across the floor with extensive movements of his arms-and the two controllers need to hold onto his arms all the time, i.e. they need to follow all his movements whilst simultaneously holding with the other hand that of the other circle member next to them. The whole circle gets into motion, and this is what is so exhausting. During the sittings, Papp [sic] even has fierce and wild fits that knock the entire long and heavy figure over and roll it on the floor. [... ] The man squirmed and hit his head, shoulders, and forehead against the floor and the table legs; the chairs were thrown to the floor, and he screamed and groaned in trance. (Hellberg \& Kassal, 1934, p. 180)

These violent fits typically occurred when a trance personality named "Saol," an alleged opponent of the usual "Rabbi Isaac," appeared to take over Lajos Pap's body. During the sittings in London, Fodor (1936?) witnessed several manifestations of "Saol," and he also stated that the controls of Lajos Pap's body got lost during such fits. The most drastic of those attacks resulted in a concussion as a result of Pap's persistent hammering of his head against the wall, and was supplemented by the tearing and destroying of his séance robe.

But, according to Fodor, even the more usual "automatic" movements proved to be suspicious. In several instances, they seemed to provide the opportunity to retrieve a hidden object from potential concealments such as Lajos Pap's kidney belt or his shoes. During the sittings, Fodor dictated 
all noteworthy occurrences including precise descriptions of Lajos Pap's "automatic" movements into a microphone connected to an adjacent room where a minutes writer took notes down. Fodor was thus able to critically relate all occurrences of the sittings to the behavior of Lajos Pap, the controls exerted, and the occurring phenomena. For example, he recorded when Lajos Pap asked the controllers to move their hands from his wrists farther upward to the elbow or the upper arm (which he did several times), and which (arm) movements and phenomena then succeeded these requests. This is interesting by itself, because even in his 1938 book Chengery Pap never explicitly mentioned that the controls were often slipped upward on Lajos Pap's arms - let alone that this happened at the medium's request. Still, on the four infrared photographs included in Chengery Pap's book that show Lajos Pap in action during séances, his right arm seems to be "controlled" at or above the elbow, not at the wrist (e.g., Figure 8A, 8B). According to the séance protocols, Lajos Pap's right arm was usually controlled by regular circle member Kornya at that time, and judging by the photographs one might suspect that the medium's arm was always more or less free during the occurrence of phenomena. ${ }^{5}$ In London, however, Fodor dictated so many details of the sittings for the protocols that Chengery Pap became annoyed and complained about this behavior. Hence, although Chengery Pap and Fodor took detailed notes of their sittings with Lajos Pap, those from Fodor seemed to be much more thorough. Most importantly, Fodor reasoned about possible agendas behind these movements, especially after it seemed to become clearer and clearer that there was something fishy about Lajos Pap's behavior and mediumship. Chengery Pap, by contrast, listed the details of the séance proceedings including the movements of Lajos Pap almost mechanically and vacuously in his protocols, and he appeared incapable of critically relating them to the development of supposed telekinetic and apport phenomena, or to question their nature and purpose. Yet, Fodor discovered even more dubious aspects of Lajos Pap's mediumship in London.

\section{Other Suspicious Aspects of Lajos Pap's Sittings in London}

- In later sittings, Lajos Pap agreed to take off his trousers. In the fourth sitting, however, only a small solid object was apported. "Rabbi Isaac" claimed that it was a glass object, and he pointed to the direction in which it was to be found. Still, it was nowhere to be found in the séance room, seemingly having vanished again. During the fifth sitting, two days later, he claimed that the sitters had not looked properly for the apport. He pointed again toward the place where it was to be found, but curiously he now stated that the object was made of iron not of glass. This time, Fodor 

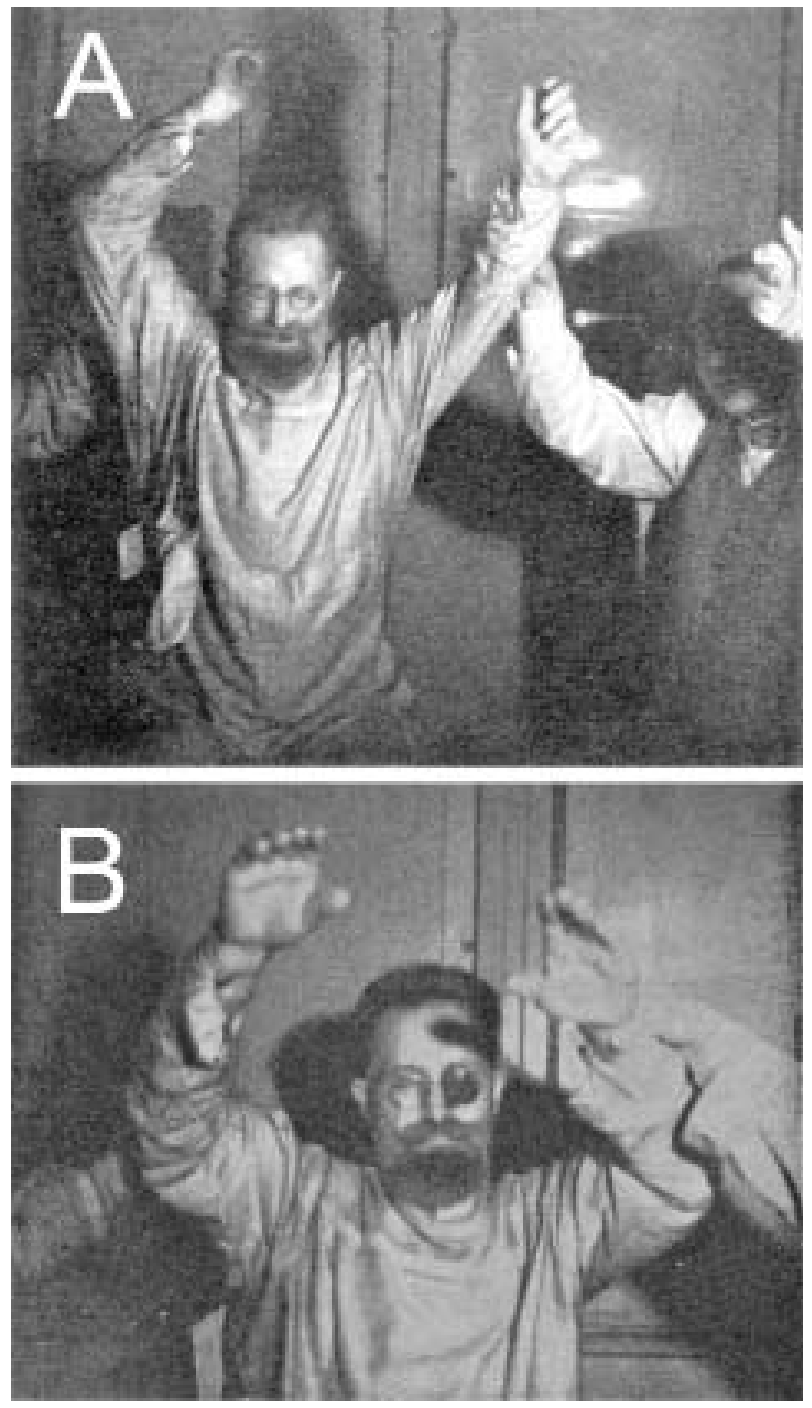

Figure 8. Infra-red photographs of Lajos Pap taken during sittings in 1937. The séance protocols read that the "hand controls" of Lajos Pap's hands were performed as usual, but the photographs clearly show that his right hand and wrist are not controlled at all. Obviously, the controller of Lajos Pap's right hand (it must be Dömötör Kornya) touches his arm somewhere above his elbow (Chengery Pap, 1938, pp. 516, 518).

(A) Lajos Pap is about to slam an apported cable on the séance table.

(B) A black unidentified object materialized and was stuck behind Lajos Pap's left spectacles glass. 
indeed found the alleged apport on a shelf. It was an old metal nut. During the sixth sitting, "Rabbi Isaac" even claimed that the nut originated from the X-ray machine that he had been examined with. These claims were wrong, however. It turned out that the cleaner of the room had found the nut in a different part of the room and placed it on the shelf so that it could easily be seen and found by anybody who entered the séance room in case it was missed. In addition, the X-ray machine had no nuts of that size, and in contrast to this unplated nut all of its nuts were nickel-plated. It became obvious that "Rabbi Isaac" was not telling the truth.

- When Lajos Pap was asked to also take off his shoes before the fifth sitting, he again flatly refused. He argued that he wore elastic laces that would render the shoes difficult to put on again, and that he could not remove his shoes anyway because he wore spats. These weak claims of defense were later replaced by saying that he was ashamed of exposing his sweaty feet. Wearing elastic shoelaces is curious conduct, especially for an apport medium, because such laces make it easier, not more difficult, to remove shoes and to slip into them again. In this sitting, a small amount of gravel stones appeared, as well as two official documents belonging to a Hungarian citizen of Budapest named "Janos Lajos Pap" (see also Chengery Pap, 1935-1936, 1938). These documents were already known to be missing in Budapest since 1930 (Anonymous, 1935g). In that year, they were accidentally lost, presumably having been delivered to a wrong address. According to Fodor, they were folded several times to a size of $5 \times 10 \mathrm{~cm}$, and looked very much as if they could have been worn inside a shoe. Immediately prior to the showers of gravel, Fodor always noted a jerking movement of Lajos Pap's arm that he controlled. When Fodor filled the collected gravel into his own shoe for a test, he found he could still walk without problems. Quite astonishingly, Chengery Pap told Fodor that the shoes (and feet) of Lajos Pap were never searched or controlled in his laboratory in Budapest prior to sittings.

- In contrast to Lajos Pap's claims, Fodor found out that his shoes could easily be removed from the luminous spats that were supposed to secure the medium's shoes and indicate their positions. Chengery Pap seemed surprised, but agreed to find a better solution for their fastening.

- During the fifth sitting, Lajos Pap claimed he produced some ectoplasm (which he sometimes did). An infrared photograph was taken, and it clearly revealed that the white substance he held in his hands was the handkerchief that he usually wore on the outside of his séance robe, and that was missing from its usual place. Chengery Pap (1938) later claimed that "Rabbi Isaac" was only making a joke when he stated that the handkerchief was ectoplasm. 
- Apart from the apport of a small gold coin in the ninth sitting, no events of potential significance occurred in the remaining sittings, before and during which Lajos Pap was controlled "from tip to toe" in a more proper way. Chengery Pap recognized the apported gold coin, and stated it belonged to a secret cache in his own suitcase which was deposited in Lajos Pap's (!) hotel room (see also Fodor, 1959). As the hotel was located very close to the séance room, Chengery Pap and Lajos Pap led Fodor, his wife, and another sitter, Mr. Becker, to the hotel to check this cache. Fodor, his wife, and Mr. Becker noted that the linen cover of the suitcase was loose and fastened again with glue that was still wet. Allegedly, it was plain that the suitcase's cache had been opened just recently. According to Fodor, Lajos Pap tried to distract their attention and pushed Mrs. Fodor's hand away, while Chengery Pap was almost "jumping around with suppressed excitement" because indeed, the gold coin in question was missing from the cache (Fodor, 1936?, p. 48). Yet, quite peculiarly and without explaining why, Fodor decided not to confront the medium and Chengery Pap about their discovery. Regarding the appearance of the gold coin in the séance room, Fodor mused that it might well have been hidden in Lajos Pap's nose. The tenth and final sitting, when his nose was properly controlled, was completely blank.

In sum, Fodor concluded that Lajos Pap's ability to produce apports was not supported by the results obtained during the sittings in London. This opinion was shaped by his observation that "the manifestations appeared to be rooted in the loopholes only, and petered out as the loopholes were stopped" (Fodor, 1936?, p. 50). Chengery Pap (1938), on the other hand, complained vigorously about the bad behavior of Fodor, the unfavorable conditions of the sittings, the mistrustful atmosphere, and attributed his medium's failure to produce satisfying results to these allegedly hostile circumstances - but without citing Fodor's findings and report in his book (admittedly, it seems that Fodor's report was and is not widely known in continental Europe; and perhaps even Chengery Pap didn't know about it). However, Fodor was initially positively intrigued by the possibility that Lajos Pap's phenomena might be genuine, and he cannot be blamed for radiating an inappropriate skepticism or negativism. In any case, Lajos Pap did not feel inclined to hold further sittings in the months following his return from London in 1935. The first séance in Chengery Pap's laboratory after the London debacle dates to January 27, 1936. 


\section{More Dubious Aspects of Lajos Pap's Mediumship and of Chengery Pap's} Presentation of It

Apart from the suspicious aspects of Lajos Pap's mediumship described above, I'd like to add a few more considerations regarding its presentation in Chengery Pap's book. In general, it is apparent that on several occasions the author aimed at eliminating doubts regarding Lajos Pap's phenomena in rather naïve and unconvincing ways. For example, when discussing the possibilities of fraud, he presented photographs of the right hands of Lajos Pap and an amateur magician held next to each other (Chengery Pap, 1938, p. 53). This comparison is supposed to show that the large hands of carpenter Pap were "entirely unusable" to perform sleight of hand and magician's tricks. Indeed, the hand of Pap looks a little broader on close inspection, and its fingers minimally thicker than that of the magician. Yet, the purportedly decisive difference in their size is mainly achieved by the effect of positioning their fingers differently: The magician's fingers are held together, whereas Lajos Pap's fingers are spread apart. The manner in which these pictures are presented and the accompanying lack of critical reasoning by Chengery Pap, who often stressed his critical approach, are irritating. But even if the latter's hands were considerably more massive, it simply cannot be inferred that he would be incapable of producing tricks in the dark. The fact that Chengery Pap was not an appropriately objective and critical séance leader is, apart from Fodor's experiences with him, also evidenced by the following considerations:

- Although Chengery Pap was the formal leader of the séances, their course was almost exclusively determined by the different personalities manifesting through Lajos Pap. All critical steps were only undertaken after the medium's consent or at his demand. For example, he instructed the sitters about how and when his body was to be controlled, and when the luminous basket and other objects were to be controlled during the séances. Also, he was the one who switched the bright light on and off during the sittings, gave the signals for taking infrared photographs, etc. In the cases where there was even a slight distrust or tighter controls seemed desirable, such as in Sweden or London, large parts of the séances were dominated by "Saol" who was practically uncontrollable.

- Chengery Pap frequently stressed that the light conditions in his laboratory were very good, especially because of the numerous phosphorescent plates on the walls. It is curious, however, that before large-scale phenomena or apports occurred, "Rabbi Isaac" almost always demanded that a considerable number of these luminous plates needed to be turned around. For example, "Rabbi Isaac" demanded that 8 of 
the 10 plates in the laboratory be turned around before the snow apport and other remarkable apports occurred-which must have rendered the room considerably darker. But, while repeatedly stressing the good light conditions during the séances, Chengery Pap never described the light conditions when almost all the luminous plates on the walls were turned around. He only mentioned these quite important changes of the light conditions in the séance room casually and never discussed their potential significance. In addition, and as described already earlier, Lajos Pap usually turned his back toward the circle center whenever he apported objects or liquids, and he even left the circle and turned his back to it in the dark at the end of each sitting to "demagnetize" himself - an odd custom not known from any other physical medium. Was there something he needed to hide or fix before the lights were finally turned on? Still, Chengery Pap didn't note anything suspicious in these behaviors.

- It is furthermore obvious that the liquids were not apported directly into the bottles. Rather, the liquids were always poured into the open bottles from outside, which was indicated by the respective milking and dripping noises, and by the honey that apparently missed the bottle and fell to the floor. But of course, apporting objects directly into the bottles would have been much more evidential, especially if they had been closed and sealed, or if the opening was too small to pass them through. Also, the dirty snow was seemingly apported as one piece, as indicated by the puddle on the floor precisely at the spot where Lajos Pap stood when he snatched tiny snowballs out of the air one after the other over several minutes.

- Also with regard to physical objects, it remains unclear why Chengery Pap didn't guide the mediums to deport objects from locked containments, or let them materialize them inside a sealed container or even bottles with a small neck, instead of using an entire laboratory or séance room. The smaller the experimental setup is, the better it can be controlled. The reader only learns very casually that such stricter experiments typically didn't work, and no further information is given. Nevertheless, there were a few exceptions such as the marked cardboard pieces that were supposedly deported from their envelope that had lain in a locked cupboard.

- A close look at the phenomenology of insect apports received in Budapest indicates that they were exposed to some kind of physical manipulation. Whereas the more solid and sturdy insects like beetles were usually alive after the apport, many of the more fragile insects like butterflies and small dragonflies were dead upon arriving, even when they "materialized" inside the basket and were carefully poured onto the luminous plate on the table. Supposing that all insects were somehow "materialized" in the air in pretty much the same manner, this difference 
in their survival rate should not be expected. Moreover, it is noteworthy that stone and metal objects apported by Lajos Pap were never warm or hot (Chengery Pap, 1938, p. 150), as sometimes reported from poltergeist cases (Gauld \& Cornell, 1979) and a few other apport mediums (e.g., Ludwiger \& Nahm, 2016).

- It is peculiar that Lajos Pap not only wore a kidney belt but also elastic laces in his shoes, and that these shoes were never searched. Perhaps Chengery Pap wasn't even aware that Lajos Pap wore elastic laces-just as he wasn't aware that the medium could easily slip out of the "secure" spats around his feet. It took Fodor only a few sittings to find all this outwhereas Chengery Pap had already experimented with Lajos Pap for years without noticing such drastic loopholes in his protocols and their potential significance. Yet, Chengery Pap should have been warned. As Besterman (1929) described, he noted that Molnar had slipped out of the luminous strap around his feet during a table session, and he informed Chengery Pap about it. He then suggested that he fasten the straps above the ankle, and he predicted that Molnar would either protest against this innovation or that drastically reduced phenomena would occur. He was right in both regards: Molnar first protested fervently against applying the new fastening technique, but when he was persuaded to still give it a try, there were no phenomena and Molnar claimed to be sick. Nevertheless, Chengery Pap returned to the former method of fastening the straps after this affair, and the table then moved as it did before (Chengery Pap, 1938, p. 383). However, Chengery Pap didn't explicitly mention this peculiar episode with Besterman in his book.

- On several occasions, Lajos Pap apported objects from seemingly locked places, including Chengery Pap's own flat. However, the latter never explained these occurrences in desirable detail. When were these objects seen for the last time in their normal places, when was the last time Lajos Pap visited the locations in question, where and how were the keys needed to reach these objects hidden, and was there a possibility of secretly reproducing a second key? Impressive as these apports from locked places seem at first sight, the episode of the apported gold coin in London shows that much more care should have been applied, and also with regard to reporting these apports. In many regards, crucial information about the precise circumstances of the described phenomena are lacking in Chengery Pap's book, even in the 35 more detailed descriptions of remarkable séances. As mentioned, I was not even able to find out how the notes for the protocols were taken down during the sittings in the laboratory until 1936, nor who took them down. Given that the chain of hands was never to be broken by all circle members apart from brief exceptions, a short 
explanation would have been desirable - also with regard to how the wrists of Lajos Pap continued to be controlled uninterruptedly by his neighbors when he rotated around his axis.

- Fodor (1936?. p. 11) stated that Lajos Pap's carpenter business didn't run well, and that he was often dependent on the financial support of Chengery Pap. The latter didn't explicitly write about the professional aspects of Lajos Pap's life, and he rather tried to raise the impression that his mediums gave their séances for free. But obviously, such a dependency between researcher and medium is important to know, as it might provide a strong motivation for the medium to satisfy his mentor by any means. Obviously, Chengery Pap omitted mentioning such potentially problematic aspects of his mediums and research on purpose. At least, Chengery Pap informed readers casually that Molnar used to live in an apartment belonging to him (Chengery Pap), and that the séances prior to the establishment of the metapsychical laboratory were held in Molnar's atelier in this apartment. This suggests that he also helped Molnar financially at that time. Omitting such information from his book prompts one to wonder what else Chengery Pap might have omitted or euphemized regarding the presentation of his research.

\section{Conclusion: Evaluating Chengery Pap's Investigations}

Given these shortcomings and omissions in Chengery Pap's investigation and its presentation, and several others not mentioned here, uncomfortable questions arise: What can we believe from him? How thoroughly were the controls of the men, women, and the laboratory really performed, especially after the breaks in the sittings? It seems not unlikely that the long-term circle members firmly believed in the genuineness of the phenomena as well as the honesty of the medium(s), the honesty of each other, and that they took the mutual body and dress controls increasingly laxly - a development that is well-known among researchers into physical mediumship, and which I have witnessed myself. The guest sitters, on the other hand, often visited only one séance and might not have had the courage and expertise to perform indepth body and dress controls on people they had never met before. In a later publication, Fodor (1959) suggested that much of the larger and seemingly inexplicable apports might have been smuggled into the séance room by the wife of Lajos Pap, who might have brought an unnoticed container with her. From this container, she might have provided her husband with the objects to be apported. The opportunity might have arisen when he was performing the different large-scale movements with and without the little basket. In the case of the snow apport, Fodor suggested she might have used a thermos flask. I mentioned already that, curiously, Lajos Pap's wife was the only 
circle member who didn't wear the usual séance dress.

However, always assuming that Chengery Pap was not contributing to a potential fraud himself, it remains difficult to find reasonable explanations for a number of Lajos Pap's phenomena. The following items must be considered in this regard. As mentioned earlier, Lajos Pap's wife participated in not even half of the sittings held by her husband. Of the 194 sittings covered in Chengery Pap's book, she attended only 91 sittings. Most of them took place in the new laboratory, when Molnar was not present. Of the 117 sittings Lajos Pap held without Molnar in the new laboratory, she attended 71 sittings. Indeed, she often participated in sittings with quite remarkable apports. For example, naming only some of the important apports, she was present when 59 beetles, 15 stag beetles, river crayfish, goldfinches, turtles, mice, and also the sparrow hawk appeared; similarly, when the mixture of snow and horse manure and several liquids such as 0.51 wine appeared. Nevertheless, comparable apports also occurred in her absence. For example, she was not present when the two largest river crayfish, 30 butterflies, the squirrel, and other liquids such as coffee and cream appeared, or when documents from a locked cupboard seemed to be transported into the laboratory. And although she didn't wear the typical séance robe, she wore luminous straps on her body that rendered her movements traceable, and she was (purportedly) always controlled by her neighbors who never included her husband. Supposing that Lajos Pap faked all his apports, he must have been able to do so without the help of his wife.

Did he have other confederates in the circle who helped him to dupe Chengery Pap in a similar manner to that pursued by the fraudulent medium Ladislaus Laszlo, who duped his principal investigator Vilmos Tordai with the help of conspiring circle members (Schrenck-Notzing, 1924b; Tabori 1951, 1968)? ${ }^{6}$ Or was he able to accomplish everything by himself? How did he produce nine small snowballs in the $22{ }^{\circ} \mathrm{C}$, warm séance room, two hours after the beginning of the séance? Admittedly, Lajos Pap snatched the nine snowballs from the air from 10 to 20 minutes after a break-but his body and clothes were allegedly searched in the usual way when he entered the laboratory after this break, as were those of the other séance participants; and although Chengery Pap doesn't explicitly touch upon this question, one might assume that nobody had left or entered the building during that break. How did Lajos Pap anesthetize invertebrates and vertebrates of different kinds and sizes prior to the séances, and free them in the séance room, often after the breaks, shortly before they came to life again and started to move? How did he manage to apport an envelope out of a locked cupboard, and to free the objects contained therein-apparently without opening the envelope? On some occasions, the sitters even claimed that they saw 
apported objects grow and then shrink again on the luminous plate on the table. It seems difficult (although not impossible) to find mundane answers to these questions, especially following the séance descriptions contained in Chengery Pap's book. But as demonstrated, these descriptions are biased, and most likely the supposed observations on which these descriptions were based had already been biased and misleading. On the other hand, the purposefully fraudulent production of apport phenomena on the part of Lajos Pap has never been proven - apart, perhaps, form the gold coin apport in London. Yet, we only have Fodor's word regarding this episode, and curiously he missed the opportunity to confront Chengery Pap and his medium with his finding.

Many aspects of Lajos Pap's mediumship are utterly suspicious. This may not mean much by itself, but Chengery Pap purposefully diminished or disregarded the significance of these crucially important aspects, or worse he wasn't even aware of them. This approach was fatal; especially as he knew about the fiasco with Ladislaus Laszlo that occurred in Budapest not long before he began with his own studies into physical mediumship. Ultimately, Chengery Pap discredited his own work, both as a researcher and as an author, and his voluminous monograph cannot be regarded as a trustworthy source that contains objective descriptions of what really happened in his laboratory, let alone in Molnar's atelier. Despite its impressive volume, Chengery Pap's magnum opus remained superficial, and considerations of the essential questions are lacking. Given the remarkable degree of creativity, technical skills, and unscrupulousness of fraudulent physical mediums, who sometimes even betrayed "friends" and close family members for years (Braude, 2016; Gulat-Wellenburg, Klinkowstroem, \& Rosenbusch, 1925; Moser, 1974; Nahm, 2014, 2016, 2018; Podmore, 1902; Tabori, 1951, 1968), one must consequently consider the possibility that Chengery Pap also was duped for years by his mediums and perhaps also by other circle members. Taking the conduct of many previous fraudulent mediums and my own experiences with alleged physical mediums into account, and comparing them to Lajos Pap's conduct and peculiar habits during séances, my personal perspective on the genuineness of particularly Lajos Pap's apport phenomena is, like Fodor's, pessimistic. Chengery Pap's (1938) monograph nevertheless remains a significant contribution in the history of parapsychology. Not so much because of the phenomena reported therein, however, but because it provides an illustrative example that demonstrates some of the numerous pitfalls and difficulties for investigating and reporting physical mediumship phenomena. Fodor's (1936?) report, on the other hand, represents a recommendable and instructive counter-example that demonstrates how to avoid these pitfalls. 


\section{Notes}

1 Fodor was very knowledgeable and active in the field of psychical research. For example, he founded the International Institute for Psychical Research in London in 1934 and was its research officer until 1938. He also published a highly esteemed Encyclopaedia of Psychical Science (Fodor, 1934).

2 The English literature on Maria Silbert is comparably scarce. While some psychical researchers came to a negative or, at best, a critical appraisal regarding the observed phenomena (Besterman, 1929; Prince, 1928), others seemed more impressed and recommended systematic studies (Price 1926), or were convinced of their genuineness (McKenzie, 1923, 1926). Other English sources on Silbert include Winterstein (1926) and Evian (1937?). Much more literature about this medium was written by Austrian and German authors. Most of it is quite positive, at times bordering on hagiography, but accusations of fraud also were advanced. An overview on Silbert and her life was provided by Sekanek (1959), who included many witness reports by different authors in his book. It also contains an extensive list of publications about Silbert.

3 János Toronyi was the president of the second Hungarian Metapsychical Scientific Society from its foundation in 1932 (Chengery Pap, 1932a, 1932b) to 1944 (Toronyi, 1951). Chengery Pap was its vice-president. The first Hungarian Metapsychical Society was disbanded after the scandalous affair surrounding fraudulent medium Ladislaus Laszlo in 1924; see also Note 6 (Schrenck-Notzing, 1924b; Tabori, 1951, 1968).

4 The re-creation of burned objects from ashes was an important part of alchemistic practices, then often termed "palingenesis." In the context of mediumship, such phenomena are only rarely reported. An early example concerns the alleged restoration of burnt books written by John Dee (e.g., Smith, 1909). Other anecdotes include the re-creation of a broken glass through Maria Silbert (Kasnacich, 1937), or that of a small burnt bag by medium Heinrich Melzer (Hess, 1935). A case that occurred under close observation of a critical scientist was described by Chengery Pap's colleague Blacher (1933), who also discussed the occurrence together with Chengery Pap (Chengery Pap \& Blacher, 1936; Blacher, 1937). Similarly, physician Erich Kindborg of Breslau (Wroclaw) suggested to a medium he knew for 10 years that she try palingenesis experiments as well, and the small circle allegedly succeeded (Huth, 1937, 1938; Kindborg, 1938). 
5 This lapse of Chengery Pap is reminiscent of Gustave Geley's lapse when he claimed that the hands of physical medium Eva C. were consistently held and controlled during séances while the photographs accompanying the text show that this wasn't the case (Geley, 1927).

${ }^{6}$ Laszlo produced the typical phenomena of physical mediums of that time such as telekinesis, apports, and ectoplasm. He soon became an internationally known medium because he produced these phenomena even under seemingly strict control conditions. However, it turned out that members of the Hungarian Metapsychical Society acted as confederates. For example, one of them prepared the "ectoplasm" together with Laszlo, and also helped him to introduce supposed apports into the séance room. The unmasking of Laszlo caused quite a stir in Hungary; in particular, Tordai as chief investigator of the medium and president of the Hungarian Metapsychical Society was harshly blamed and ridiculed in public.

\section{References}

Anonymous (1934a, July 27). Medium showers oats. Light, 54(2794), 451.

Anonymous (1934b). Les "singuliers" apports d'un medium. Revue Métapsychique, 14, 68-69.

Anonymous (1934c, July 20). Snake apports. Light, 54 (2793), 433.

Anonymous (1935a, February 28). Apport medium. Light, 55(2825), 138.

Anonymous (1935b, April 18). Coming of Lajos Pap. Light, 55, 249.

Anonymous (1935c). Lajos Pap in London. Light, 55, 279.

Anonymous (1935d, May 16). Snake apport. Light, 55, 313.

Anonymous (1935e, June 13). Mr. Lajos Pap. Light, 55, 377.

Anonymous (1935f). A qui appartiennent les objets"apportés"? Revue Métapsychique, 15, 155-156.

Anonymous (1935g). Apports in court. Missing Budapest documents turn up in London. Light, 55(2938), 346.

Anonymous (1938a). Unter dem Titel “Uj látóhatárok felé . . . " Zeitschrift für Metapsychische Forschung, 9, 127-128.

Anonymous (1938b). Uj Làtohatarok Felé. Revue Métapsychique, 18, 140.

Besterman, T. (1929). Report of a four months' tour of psychical investigation. Proceedings of the Society for Psychical Research, 38, 409-480.

Blacher, C. (1926, March). Ein unbezweifelbares Apporterlebnis. Zeitschrift für Parapsychologie, 1(3), 138-142.

Blacher, C. (1931-1932). Apport-Beobachtungen. Zeitschrift für Metapsychische Forschung, 2:201-206, 239-243, 271-274; 3,181-188, 254-259, 352.

Blacher, C. (1933). Apportstudien. Leipzig: Mutze.

Blacher, C. (1937). Kann Verbranntes wiedererstehen? Metapsychologische experimentelle Beiträge zum Phönixproblem. Was weiter? Rückschau und Schlüsse. Zeitschrift für Metapsychische Forschung, 8, 45-54.

Bottazzi, F. (2011). Mediumistic Phenomena: Observed in a Series of Sessions with Eusapia Palladino translated by I. Routti \& A. Giuditta. Princeton, NJ: ICRL Press.

Braude, S. E. (2016). Follow-up investigation of the Felix Circle. Journal of Scientific Exploration, 30(1), 27-55.

Chengery Pap, E. (1930-1931). Über die Sitzungen mit den Budapester Psychitiven Lajos Papp und Tibor Molnar. Zeitschrift für Metapsychische Forschung, 1, 414-416; 2, 11-17. 
Chengery Pap, E. (1932a, June). Konstituierung der Metapsychischen Gesellschaft in Ungarn. Zeitschrift für Parapsychologie, 7(6):281-282.

Chengery Pap, E. (1932b). Konstituierung einer zweiten Ungarischen Gesellschaft für metapsychische Forschung in Budapest. Zeitschrift für Metapsychische Forschung, 3, 313.

Chengery Pap, E. (1933a). Merkwürdige Apporte in Budapest. Zeitschrift für Parapsychologie, 8, 472-473.

Chengery Pap, E. (1933b). The mediumship of Lajos Pap: Remarkable variety of pyschic phenomena. Light, 53(2762), 795.

Chengery Pap, E. (1934, May). Der abenteuerliche Fall des ungarischen Mediums Lajos Pap in Schweden und sein dortiges Martyrium. Zeitschrift für Parapsychologie, 9(5), 218-220.

Chengery Pap, E. (1935). Sitzung mit dem ungarischen Medium Lajos Pap im Metapsychischen Laboratorium von Dr. Chengery-Pap. Zeitschrift für Metapsychische Forschung, 6(49), 49-54, 106-107.

Chengery Pap, E. (1935-1936). Apport-Dokumente vor dem Gericht.Zeitschrift für Metapsychische Forschung, 6, 140-146,194-199; 7, 19.

Chengery Pap, E. (1938). Új látóhatárok felé. Budapest: Attila.

Chengery Pap, E. (1941). Az okkultizmus köréböl. Budapest: Urbányi-Nyomda Budapest.

Chengery Pap, E., \& Blacher, C. (1936). Kann Verbranntes wiedererstehen? Metapsychologische experimentelle Beiträge zum Phönixproblem. Wie soll man berichten? Zeitschrift für Metapsychische Forschung, 7, 137-142,185-192.

Evian, A. (1937?). The mediumship of Maria Silbert. London: The Occult Book Society. [Presumably published in 1937.]

Fodor, N. (1933, July 14). Puzzling apport phenomena. Light, 53, 435.

Fodor, N. (1934). Encyclopaedia of psychic science. London: Arthurs Press.

Fodor, N. (1936?). The Lajos Pap experiments. Bulletin of the International Institute for Psychical Research, 2, 1-56. [Presumably published in 1936.]

Fodor, N. (1959). The haunted mind: A psychoanalyst looks at the supernatural.. New York: Helix Press.

Gauld, A., \& Cornell, A. D. (1979). Poltergeists. London: Routledge \& Kegan Paul.

Geley, G. (1927). Clairvoyance and materialisation. London: Fisher Unwin.

Gissurarson, L. R., \& Haraldsson, E. (1989). The Icelandic physical medium Indridi Indridason. Proceedings of the Society for Psychical Research, 57, 53-148.

Grosso, M. (2016). The man who could fly: St. Joseph of Copertino and the mystery of levitation. Lanham, MD: Rowman \& Littlefield.

Grosso, M. (2017). Wings of ecstasy: Domenico Bernini's Vita of St. Joseph of Copertino (1722) translated by C. Clough. Wroclaw, Poland: Amazon Fulfillment.

Gulat-Wellenburg, W. von, Klinckowstroem, C. von, \& Rosenbusch, H. (1925). Der Physikalische Mediumismus. Berlin: Ullstein.

Gyimesi, J. (2016). The institutionalisation of parapsychology in Hungary in the 20th century. In Okkultismus im Gehäuse edited by A. Lux \& S. Paletschek (pp. 201-224), Berlin: Walter de Gruyter.

Haraldsson, E. (2011). A perfect case? Emil Jensen in the mediumship of Indridi Indridason the fire in Copenhagen on November 24th 1905 and the discovery of Jensen's identity. Proceedings of the Society for Psychical Research, 59, 195-223.

Haraldsson, E. (2012). Further facets of Indridi Indridason's mediumship, including 'transcendental' music, direct speech, xenoglossy and light phenomena. Journal of the Society for Psychical Research, 76(3), 129-149.

Haraldsson, E., \& Gissurarson, L. R. (2015). Indridi Indridasson. The Icelandic Physical Medium. Hove: White Crow Books.

Hellberg, E., \& Kassal, G. (1934). Zur Phänomenik des Budapester Psychitiven Lajos Papp. Zeitschrift für Metapsychische Forschung, 5:177-187. 
Hess, O. (1935). Die Mediumschaft von Heinrich Melzer: nach authentischen Quellen bearbeitet und zusammengestellt. Leipzig: Mutze.

Huth, G. (1937). Die Psychophysik und ihre wundersamsten Phänomene. Wiedererstehen verbrannter Gegenstände. Das Neue Licht, 16, 238-240.

Huth, G. (1938). Das seltenste Phänomen. Weitere Verbrennungs- und Materialisationsversuche. Das Neue Licht, 17, 164-166.

Kasnacich, J. (1937). Methodologische Fragen zu den Phönix-Experimenten Riga-Budapest. Zeitschrift für Metapsychische Forschung, 8, 145-148.

Kindborg, E. (1938). Palingenesis Breslauban (pp. 368-372). In E. Chengery Pap (Ed.), Új látóhatárok felé. Budapest: Attila.

Kürthy, P. (1999). Paranormale Phänomene in Ungarn. Wegbegleiter, 4, 16-18.

Ludwiger, I. von, \& Nahm, M. (2016). Apport phenomena of medium Herbert Baumann (19111998): Report on personal experiences. Journal of Scientific Exploration, 30, 337-358.

Margittai, R. (1933). Rabbi Isaacs okkulteWundertaten in Budapest. Zeitschrift für Parapsychologie, $8,426-428$.

McKenzie, J. H. (1923). The remarkable phenomena of Frau Silbert. Psychic Science, 2, 8-44.

McKenzie, B. (1926). Frau Maria Silbert of Graz (with portrait) and her amazing phenomena. Psychic Science, 5, 98-141.

Melton, J. G. (Editor) (2001). Encyclopedia of Occultism and Parapsychology (5th ed., 2 vol.) Farmington Hills, MI: Gale.

Moser, F. (1974). Das große Buch des Okkultismus: Originalgetreue Wiedergabe das zweibändigen Werkes Okkultismus_Täuschungen und Tatsachen. Freiburg: Hermann Bauer-Verlag.

Nahm, M. (2014). The development and phenomena of a circle for physical mediumship. Journal of Scientific Exploration, 28(2), 229-283.

Nahm, M. (2016). Further comments about Kai Mügge's alleged mediumship and recent developments. Journal of Scientific Exploration, 30(1), 56-62.

Nahm, M. (2017). Selected aspects of Carlos Mirabelli's mediumship. Journal of Scientific Exploration, 31(3), 457-466.

Nahm, M. (2018). Investigating "physical mediums" via audio signal processing: A comment on a recent approach. Journal of Scientific Exploration, 32(3), 579-595.

Ochorowicz, J. (2018a). Mediumistic Phenomena, Part I, translated by C. Bernard \& Z. Weaver, edited by Z. Weaver. Journal of Scientific Exploration, 32, 79-154. [Originally published in Polish in a series of six booklets between 1913 to 1915.]

Ochorowicz, J. (2018b). Mediumistic phenomena, part II, translated by C. Bernard \& Z. Weaver, edited by Z. Weaver. Journal of Scientific Exploration, 32(2), 349-411. [Originally published in Polish in a series of six booklets between 1913 to 1915.]

Podmore, F. (1902). Modern spiritualism. A history and criticism (two volumes). London: Methuen.

Price, H. (1926). Frau Silbert and her phenomena. Journal of the American Society for Psychical Research, 20, 265-279.

Prince, W. F. (1928). Experiments with Physical Mediums in Europe. Boston, MA: Boston Society for Psychical Research.

Röthy, K. (1928a). Physikalische Phänomene in Budapest. Das Neue Licht, 7, 35-39, 90-93.

Röthy, K. (1928b). Weiteres über die physikalischen Phänomene in Budapest. Das Neue Licht, 7, 214-216.

Röthy, K. (1928c). Die neuesten Ergebnisse der physikalischen Experimente in Budapest. Das Neue Licht, 7, 241-243.

Röthy, K. (1930). Vollkommene Rehabilitierung der Budapester Medien. Das Neue Licht, 9, 142-144. Röthy, K. (1933a). Apporte von lebenden Tieren. Zeitschrift für Metapsychische Forschung, 4, 22-24. Röthy, K. (1933b). Apporte von lebenden Tieren. Das Neue Licht, 12, 299-304.

Röthy, K. (1934a). Merkwürdige neueste Apporte. Zeitschrift für Metapsychische Forschung, 5, 7678. 
Röthy, K. (1934b). Neueste Apporte. Das Neue Licht, 13, 15-17.

Röthy, K. (1935a). Überprüfung des Mediums Papp Lajos in London. Das Neue Licht, 14, 129-130. Röthy, K. (1935b). Erfolge mit dem Medium Papp Lajos in London. Das Neue Licht, 14, 154.

Röthy, K. (1938). Ein Besuch in dem metapsychischen Museum des Dr. Elémér Pap. Das Neue Licht, 17, 76-78.

Schrenck-Notzing, A. von (1924a). Experimente der Fernbewegung. Stuttgart: Union Deutsche Verlagsgesellschaft.

Schrenck-Notzing, A. von (1924b). Der Betrug des Mediums Ladislaus Laszlo. Psychische Studien, $51,129-160$.

Sekanek, R. (1959). Mutter Silbert. Tatsachen, Berichte, Dokumente. Remagen, Germany: Reichl.

Šimsa, J. (1931, November/December). Spontane Spukphänomene in Prag-Branik, 1930-31, in experimentelle über-führt. Zeitschrift für Parapsychologie, 6(11, 12), 527-539, 565-574.

Šimsa, J. (1934). Interessante Beobachtungen im physikalischen Mediumismus mit dem Prager Medium Wolf. Zeitschrift für Metapsychische Forschung, 5, 58-65, 106-110, 137-143.

Smith, C. F. (1909). John Dee (1527-1608). London: Constable.

Sünner, P. (1934). In Budapest. Zeitschrift für Parapsychologie, 9(4), 183.

Tabori, C. (1951). My occult diary. London: Rider.

Tabori, P. (1968). Companions of the unseen. New York: University Books.

Toronyi, J. (1951). Experimente mit physikalischen Medien. Neue Wissenschaft, 2, 181-188, 243250.

van Gorcum, G. (1936a). Een bezoek aan het apport-medium Lajos Pap in Budapest. Spiritische Bladen, 11, 273-277.

van Gorcum, G. (1936b). De apporten van Lajos Pap. Spiritische Bladen, 11, 355.

Walther, G. (1938). Unsere Bücher; “Uj látohatárok felé." Das Neue Licht, 17, 82-83.

Weaver, Z. (2015). Other realities? The enigma of Franek Kluski's mediumship. Hove: White Crow. Winterstein, A. (1926). A sitting with Frau Silbert. Journal of the American Society for Psychical Research, 20, 577-584. 